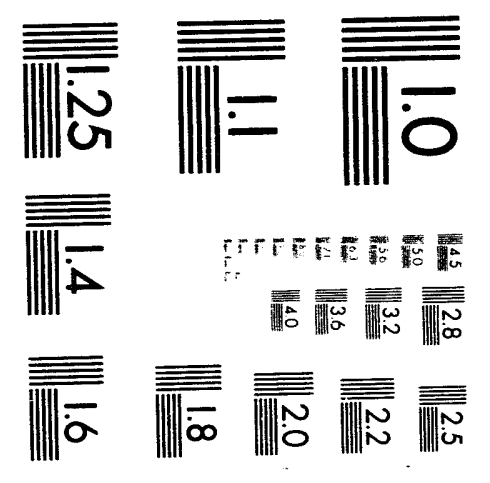



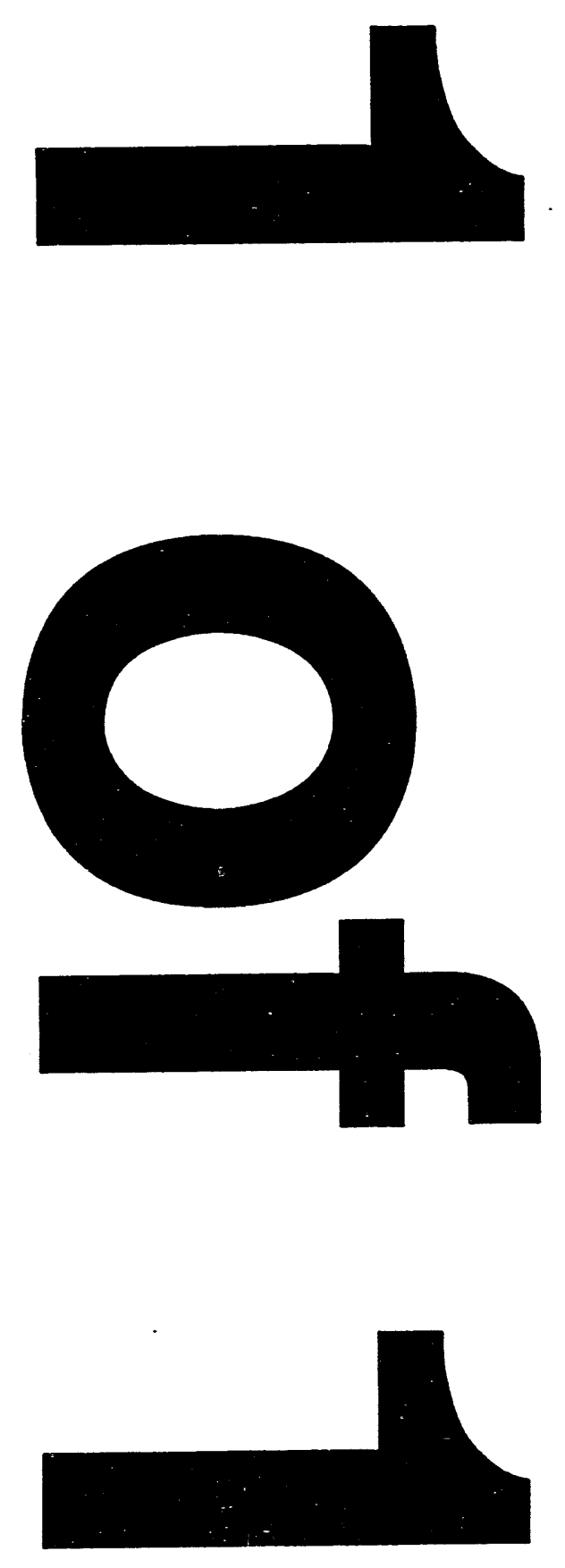
ORNL/TM-12112

\title{
ACQUISITION INFORMATION MANAGEMENT SYSTEM TELECOMMUNICATION SITE SURVEY RESULTS
}

\author{
Kerry Hake \\ Billie Key \\ COR, Inc.
}

August 1993

\author{
Prepared for the \\ The Assistant Secretary of the U.S. Army \\ for Research and Development, Acquisition \\ Office of the Product Manager, \\ Acquisition Information Management \\ Fort Belvoir, Virginia \\ under \\ Interagency Agreement DOE No. 1405-1351-A1
}

\author{
Prepared by the \\ OAK RIDGE NATIONAL LABORATORY \\ Oak Ridge, Tennessee 37831 \\ managed by \\ MARTIN MARIETTA ENERGY SYSTEMS, INC. \\ for the \\ U.S. DEPARTMENT OF ENERGY \\ under contract DE-AC05-84OR21400
}


TABLE OF CONTENTS

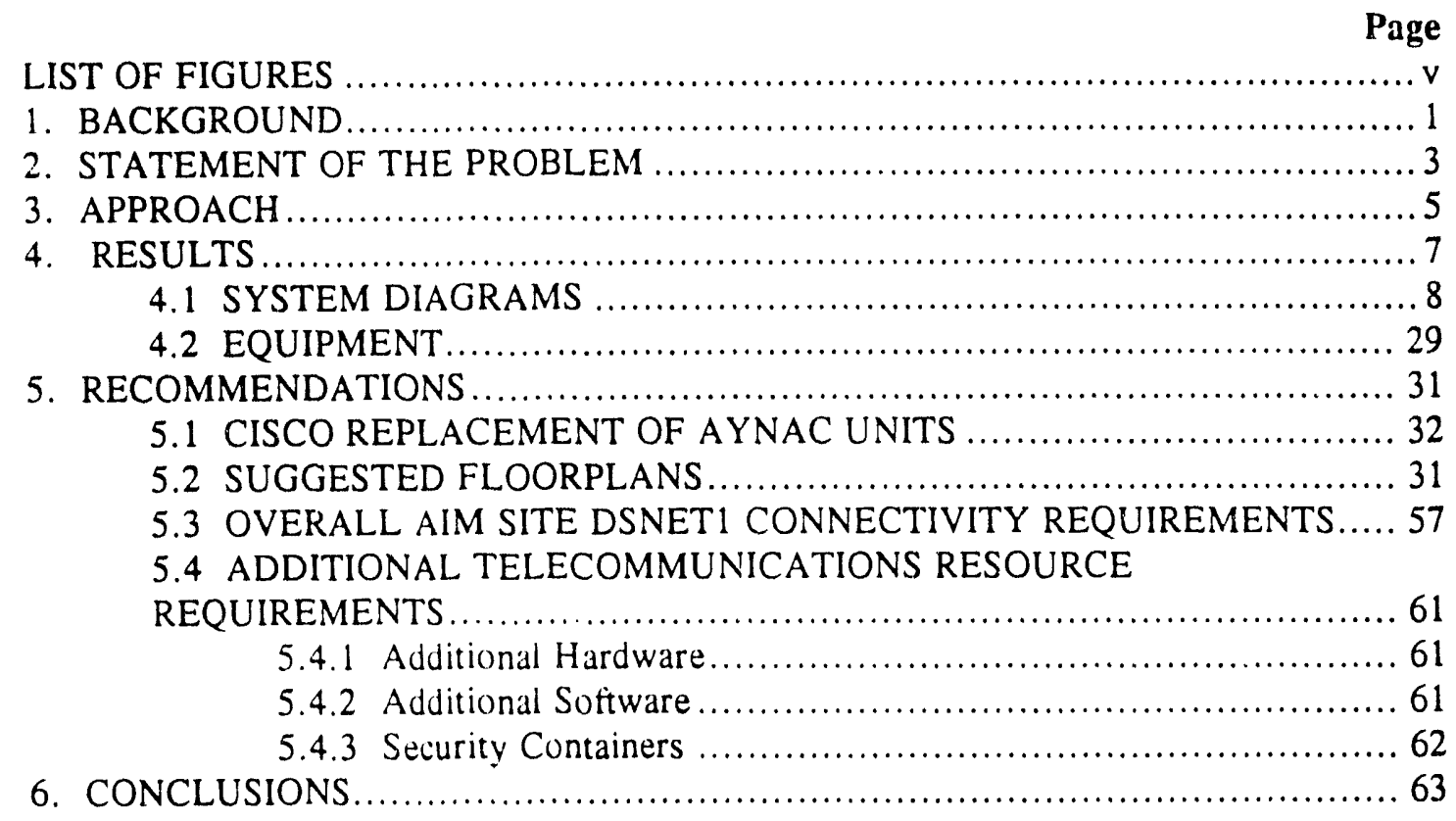




\section{LIST OF FIGURES}

\begin{tabular}{|c|c|}
\hline Figure 1 & 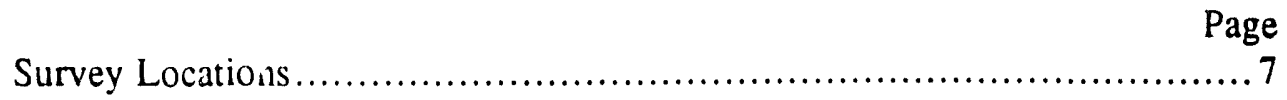 \\
\hline Figure 2 & 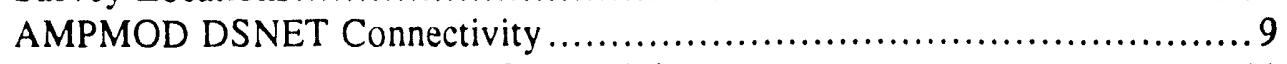 \\
\hline Figure 3 & Picatinny Arsenal AMPMOD Connectivity ............................. 11 \\
\hline Figure 4 & Fort Monmouth AMPMOD Connectivity .................................. 13 \\
\hline Figure 5 & Redstone AMPMOD Connectivity............. \\
\hline Figure 6 & 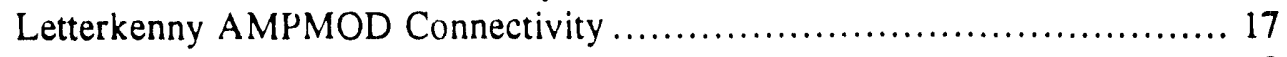 \\
\hline Figure 7 & RDAISA-R AMPMOD Connectivity ..................................... 19 \\
\hline Figure 8 & 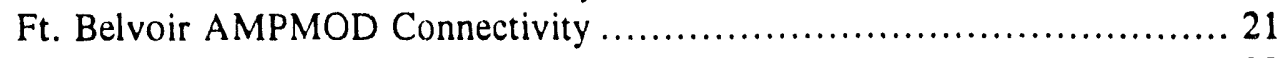 \\
\hline Figure 9 & St. Louis AMPMOD Connectivity ................. \\
\hline Figure 10 & Warren AMPMOD Connectivity......................................... 25 \\
\hline Figure 11 & Vint Hill AMPMOD Connectivity....................................... 27 \\
\hline Figure 12 & 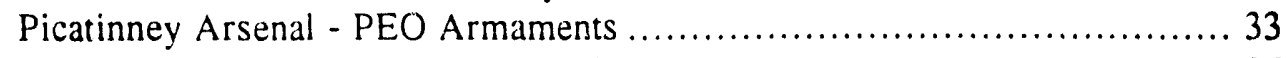 \\
\hline Figure 13 & Fort Monmouth - PEO Communications ............. \\
\hline Figure 14 & Fort Monmouth - PEO Command and Control............................ 37 \\
\hline Figure 15 & Redstone Arsenal - PEO Fire Support Systems ............................ 39 \\
\hline Figure 16 & Redstone Arsenal - PEO Air Defense Systems ........................ \\
\hline Figure 17 & Letterkenny Army Depot - Systems Information Management Agency ....... 43 \\
\hline Figure 18 & $\begin{array}{l}\text { Radford Army Ammunitions Plant - Research, Development and Acquisition } \\
\text { Information Suporrt Activity ............................................. } 45\end{array}$ \\
\hline Figure 19 & Fort Belvoir - PM Acquisition Information Management .................. 47 \\
\hline Figure 20 & St. Louis Federal Center - PEO Aviation Support Command... \\
\hline Figure 21 & Tank and Automotive Command - PEO Combat Support..................... 51 \\
\hline Figure 22 & Tank and Automotive Command - PEO Armored Systems Modernization.... 53 \\
\hline Figure 23 & Vint Hill Farms - PEO Intelligence and Electronic Warfare .................... 55 \\
\hline Figure 24 & Recommended AIM Site DSNET1 Connectivity.............. \\
\hline Figure 25 & Proposed Security Container for AT\&T 3B2... \\
\hline
\end{tabular}




\section{BACKGROUND}

The Assistant Secretary of the Army for Research, Development, and Acquisition has assigned to the Project Manager, Acquisition Information Management (PM-AIM), program management responsibilities for the Army Acquisition Management system development. Thes responsibilities include the development of the Acquisition Information Management Network (AIMNET), a secure classified network.

PM-AIM also has oversight of the Army Material Plan Modernization (AMPMOD) secure telecommunications network.

The AIM project plans require assessment of the current capabilities of AIMNET, the AMPMOD Network, the development of plans for transition of these to the Defense Data Network (DDN) Defense Secure Network I (DSNET1, where the I refers to Secret level), the deployment of an AIM Program Manager Information Sy'stem (PMIS), a Project Manager/Program Executive Officer AIMNET workstation that will run the Program Manager Support System (PMSS) software, and the development of plans for and analysis of telecommunications and hardwaresoftware system enhancements.

PM-AIM has requested assistance in determining the existing, telecommunications resources available in the Army acquisition community and recommending appropriate changes. This paper reports the status of the site survey task in the statement of work. 


\section{STATEMENT OF THE PROBLEM}

The Army acquisition community currently uses a dedicated, point-to-point secure computer network for AMPMOD. It must transition to the DOD supplied DSNET1. This is one of the first networks of this size to begin the transition. The type and amount of computing resources available at individual sites may or may not meet the new network requirements. This task surveys these existing telecommunications resources available in the Army acquisition community. It documents existing communication equipment, computer hardware, associated software, and recommends appropriate changes 


\section{APPROACH}

An AMPMOD/DSNET connectivity overview diagram was developed. Appropriate sites were selected and visited. Equipment, cabling, and software were located. inspected, and evaluated for DSNET capability. A site conectivity diagram was developed along with a list of pertinent equipment and software. Recommendations included a list of suggested equipment and software procurements and floor plans for each of the sites visited. An overview diagram of DSNETI connectivity requirements was developed. 


\section{RESULTS}

The sponsor directed that surveys be conducted at 9 of 12 potential locations (Figure 1).

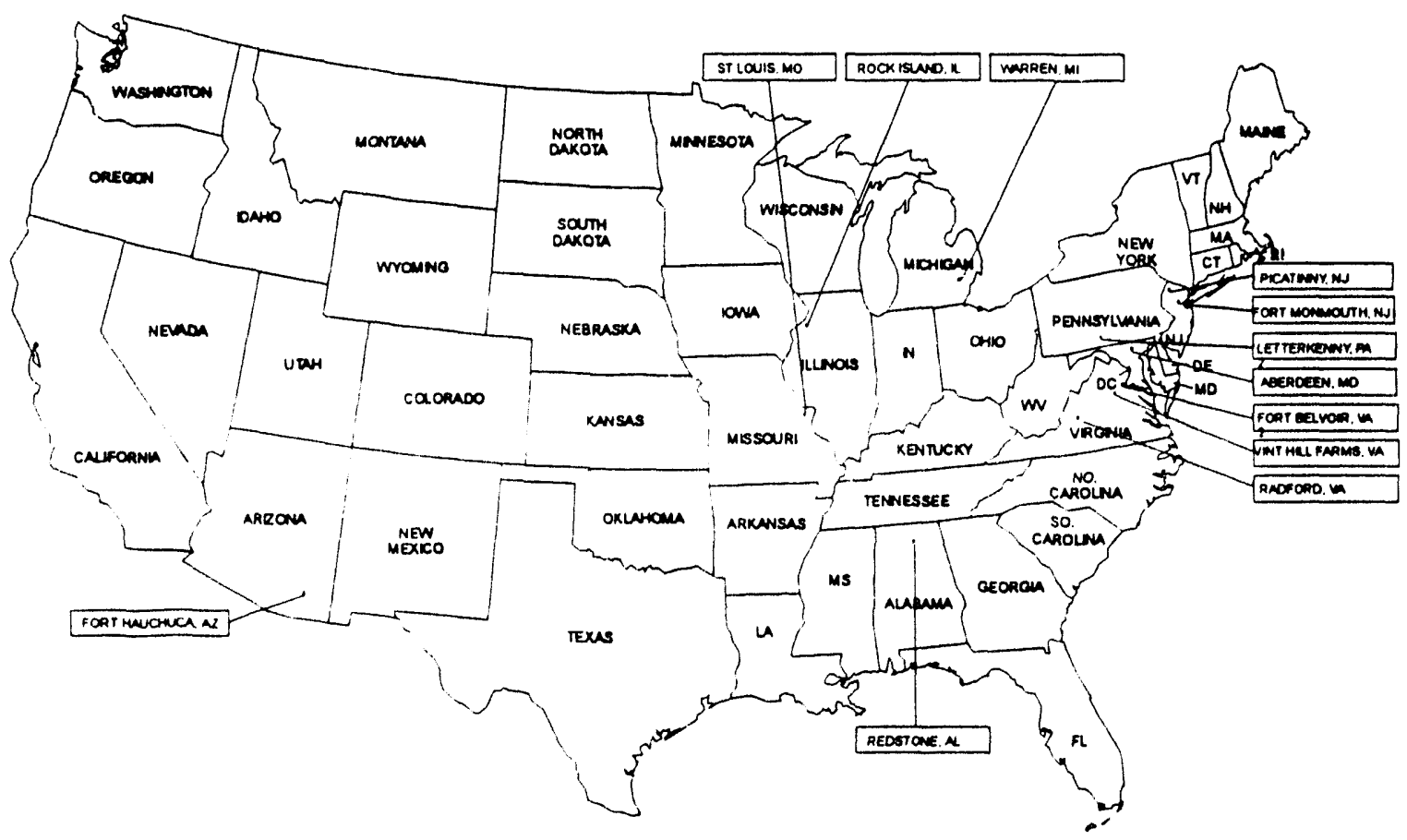

Figure 1. Survey Locations.

The following acquisition community activity is associated with each site:

\section{LOCATION \\ Aberdeen, MD \\ Dover, NJ \\ Eatontown, NJ \\ Huntsville, $\mathrm{AL}$ \\ Aberdeen Proving Grounds \\ Picatinney Arsenal \\ Fort Monmouth \\ Redstone Arsenal}

Letterkenny, PA

Radford, VA

Rock Island, IL

Sierra Vista, AZ

Springfield, VA

St. Louis, MO

Warren, MI

Warrenton, VA Vint Hill Farms

Letterkenny Army Depot

Rock Island Arsenal

Fort Huachuca

Fort Belvoir

St. Louis Federal Center

\section{ACTIVITY - PEO}

Radford Army Ammunitions Plant Research, Development and Acquistion

Tank and Automotive Command

*Not surveyed per sponsor direction.
System Information Management Agency
Research, Development and Acquistion
Information Support Activity

Armaments

Communications, Command and Control Fire Support Systems, Air Defense

Systems

*

Acquisicion Information Management-PM

Aviation Support Command

Combat Support, Armored Systems

Modernization

Intelligence and Electronic Warfare 


\subsection{SYSTEM DIAGRAMS}

A system diagram was developed to show the overall connectivity of the AMIMOD network (Figure 2).

A system diagram was developed for each location surveyed (Figures 3-11). The information shown includes the identification and location of terminals, cluster controllers, printers, mainframes, front end processors, gateways, cryptographic equiment (a.k.a. cryptos), modems, and communication connectivity to include the DSNET node. It should also be noted that these diagrams show proposed PEO/PM connectivity for the PM-AIM provided AT\&T computers. 


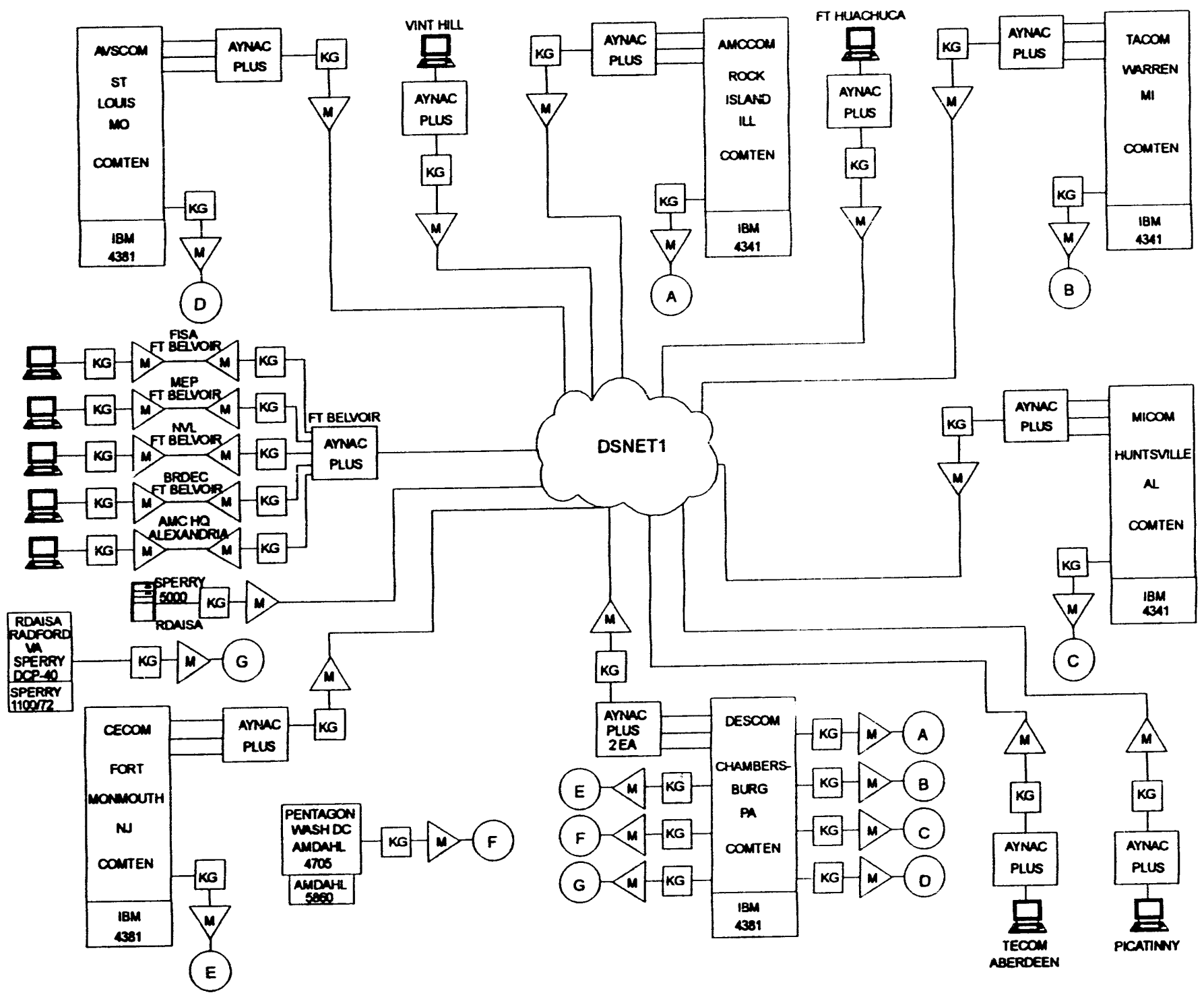

Figure 2. AMPMOD DSNET Connectivity. 


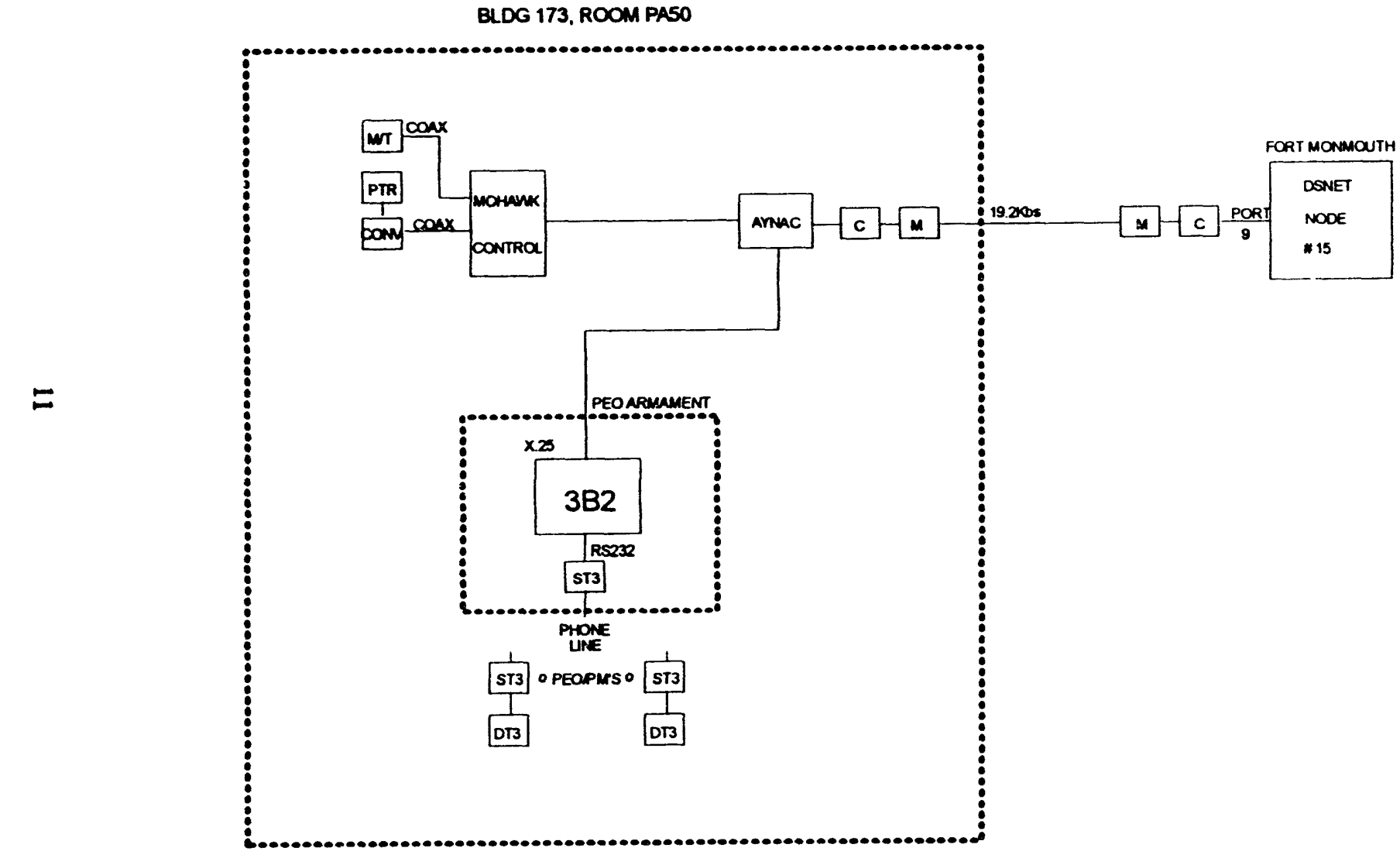

c CRrPTOunt

SSC SAFE WTH CRYPTOUNAT

MT] Momann

DT3. DESK TOP III COMPUTER

EOMI COAX TO CENTRONAC CONERTER

TPC] TEMPEST PERSONNEL COMPUTER

PTR PRINTER

ST3 SECURE TELEPHONE

M MOOEM

Figure 3. Picatinny Arsenal AMPMOD Connectivity 


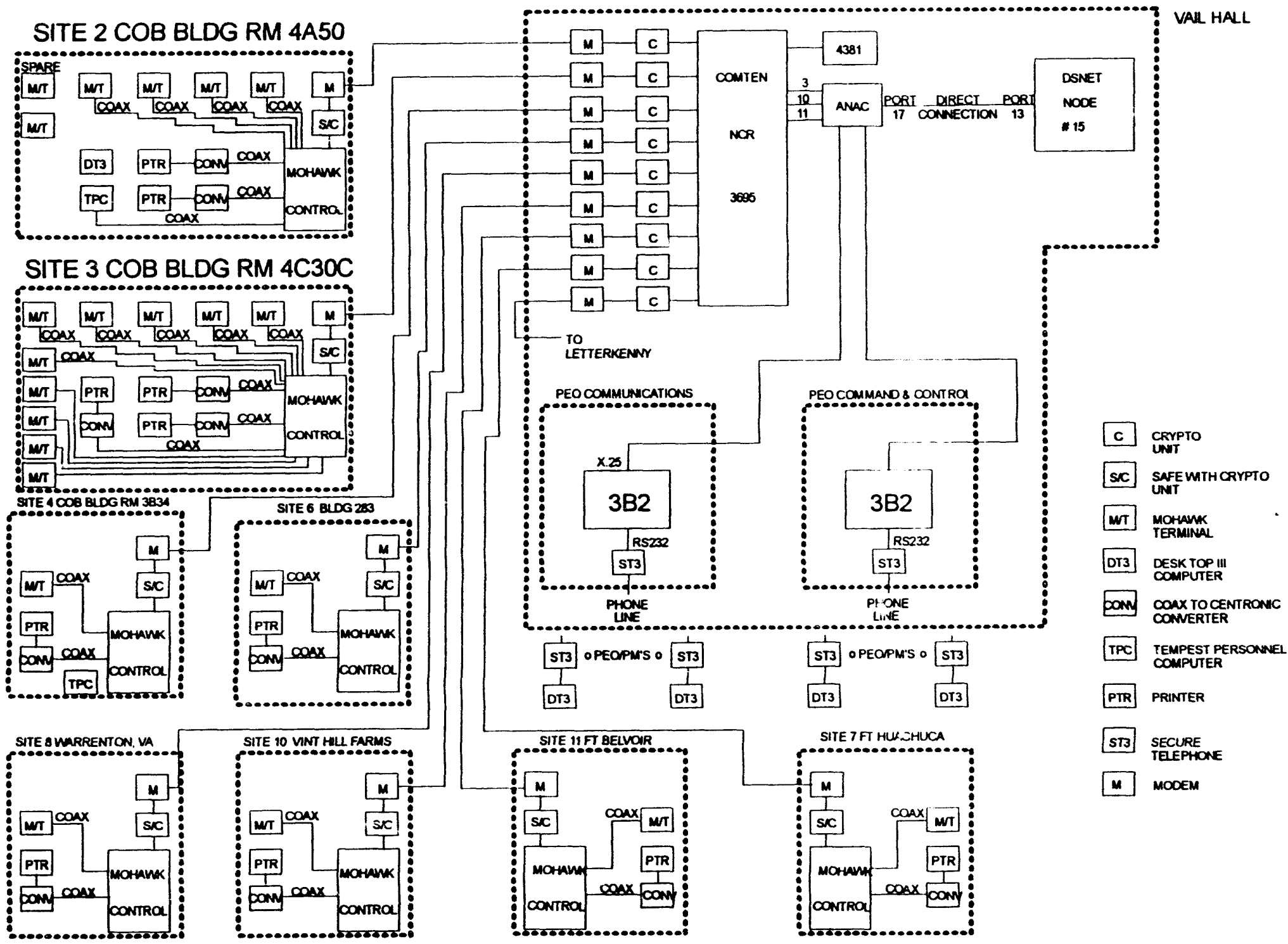

Figure 4. Fort Monmouth AMPMOD Connectivity. 


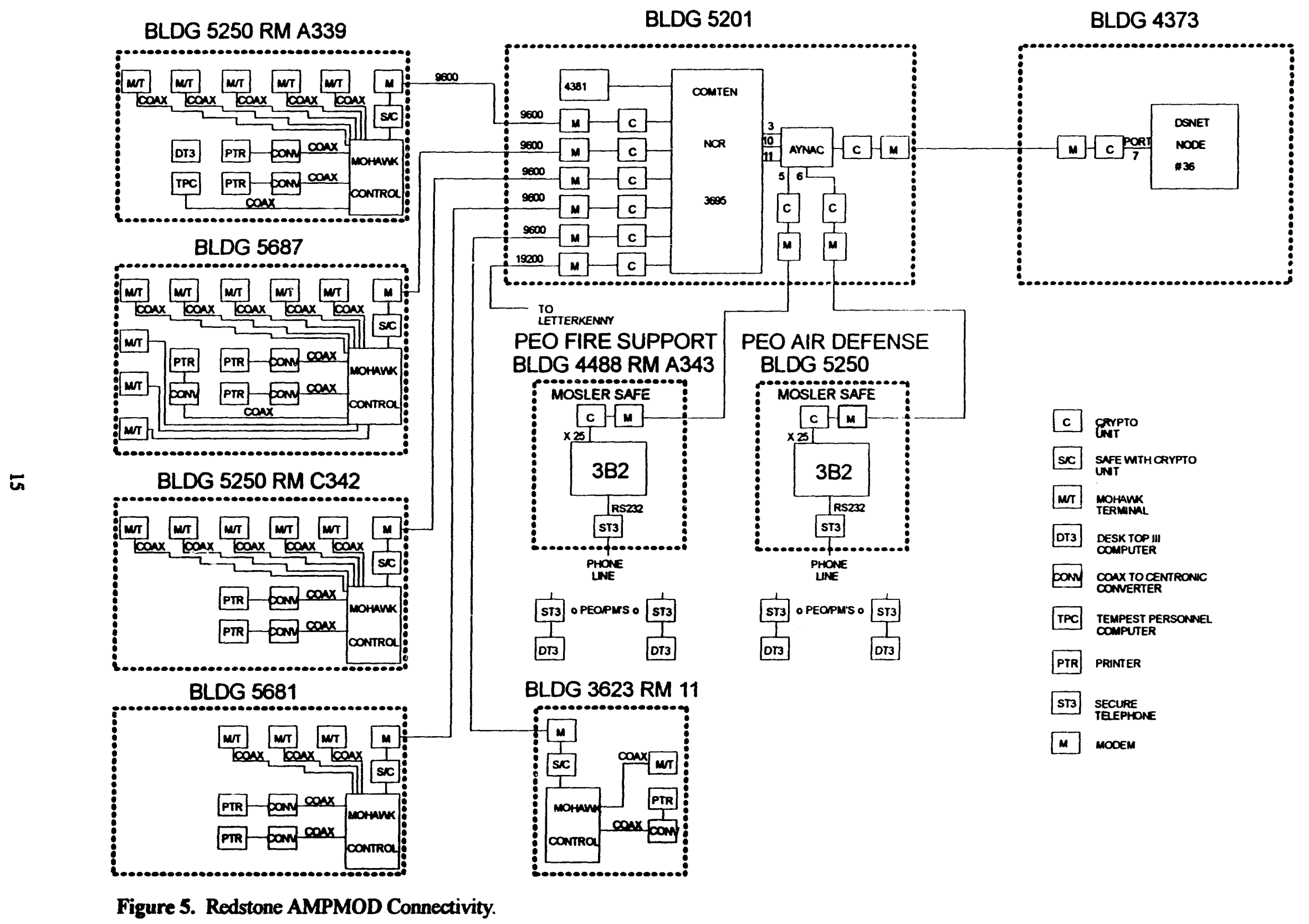




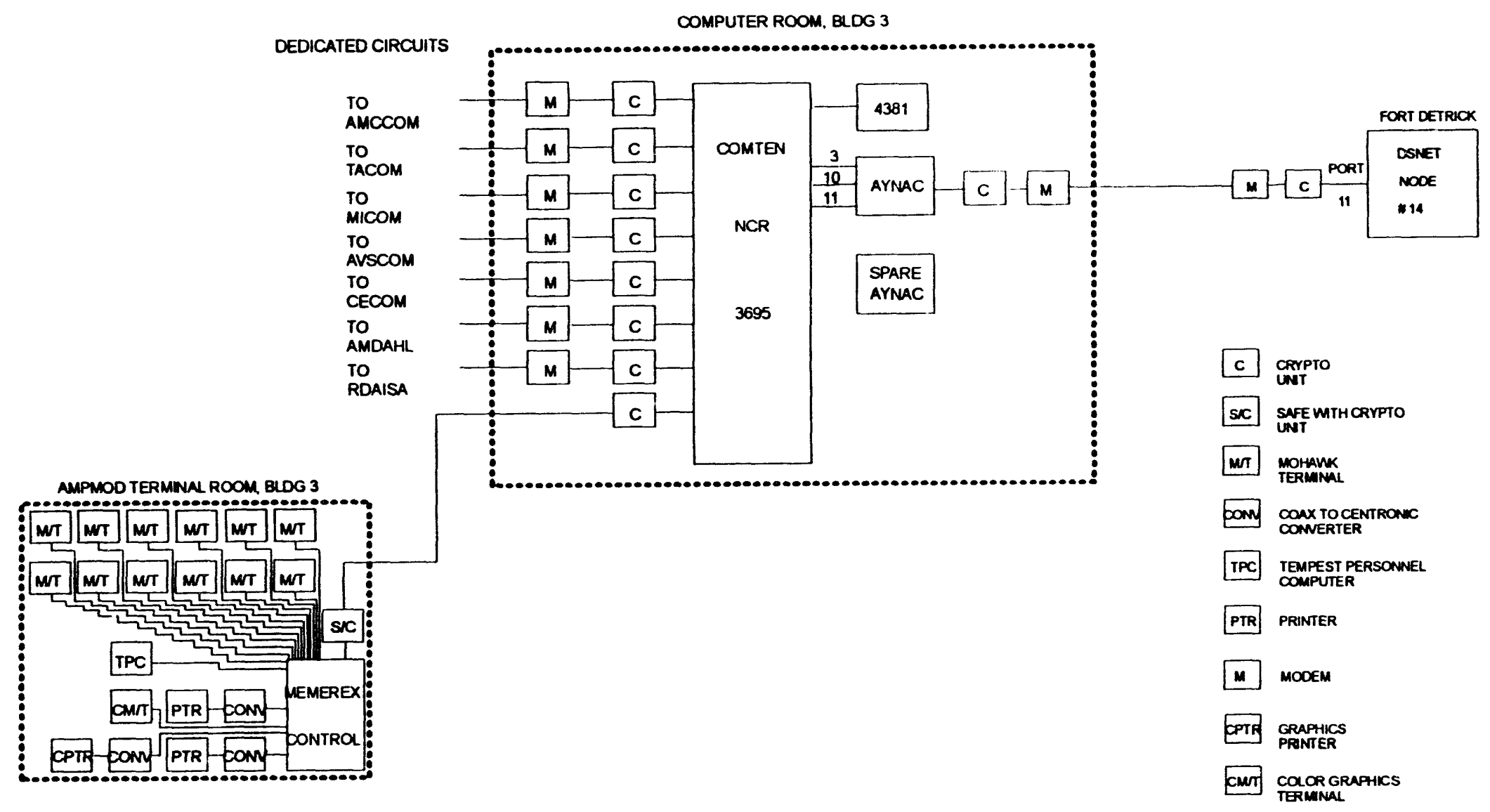

Figure 6. Letterkenny AMPMOD Connectivity 


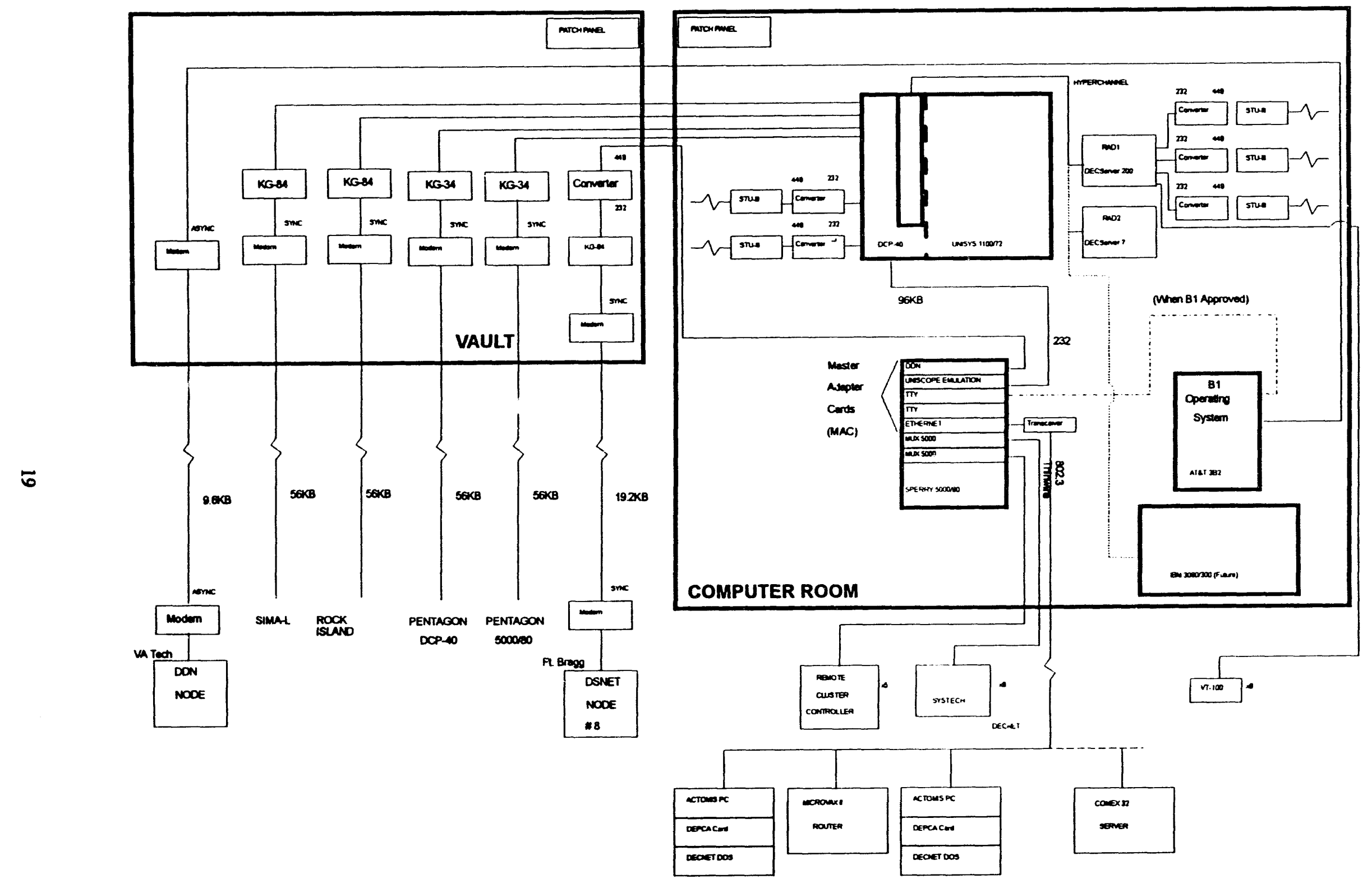

Figure 7. RDAISA-R AMPMOD innectivity. 

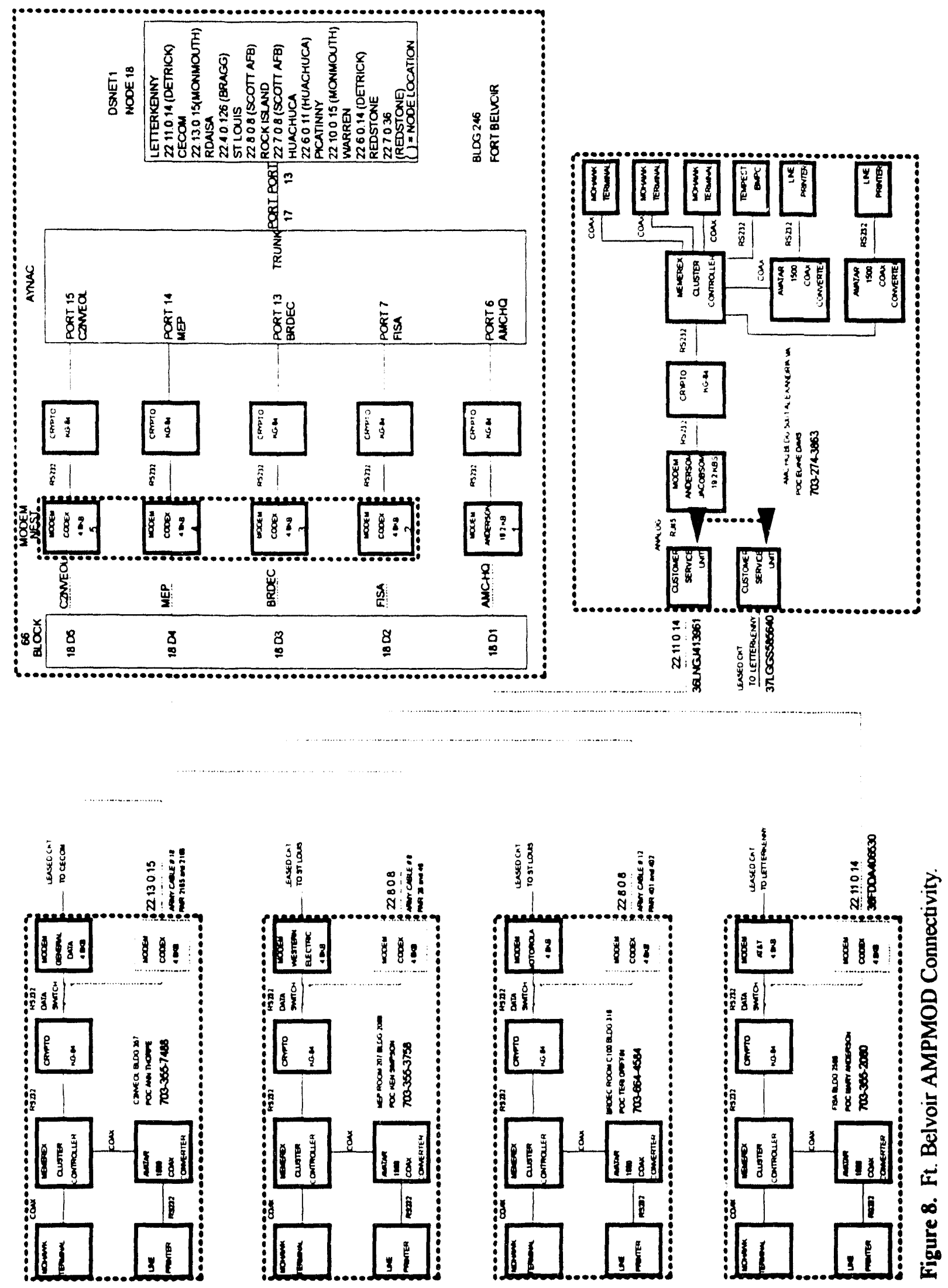
STE 6QUDG 110 ST LOUIS

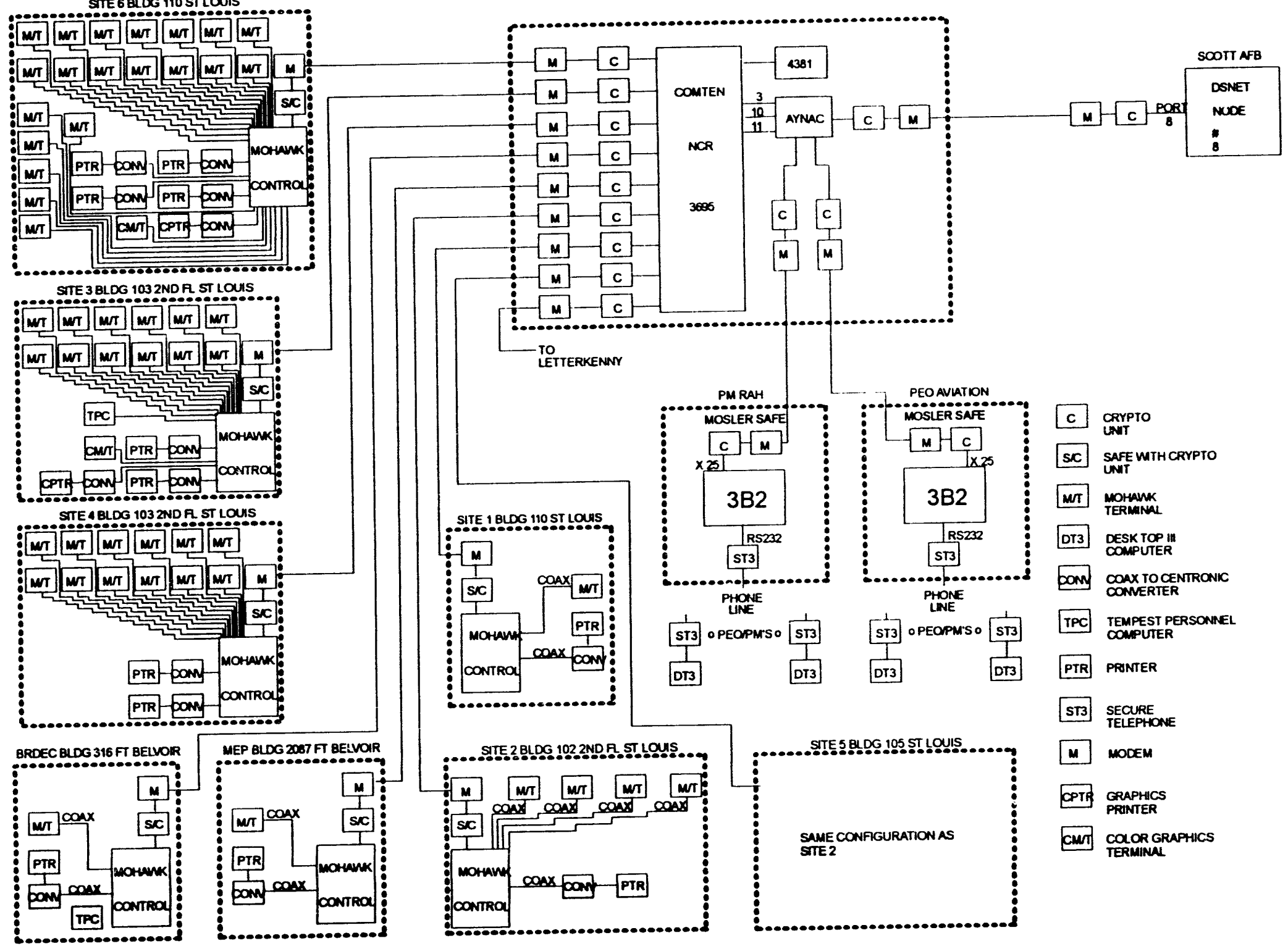

Figure 9. St. Louis AMPMOD Connectivity. 


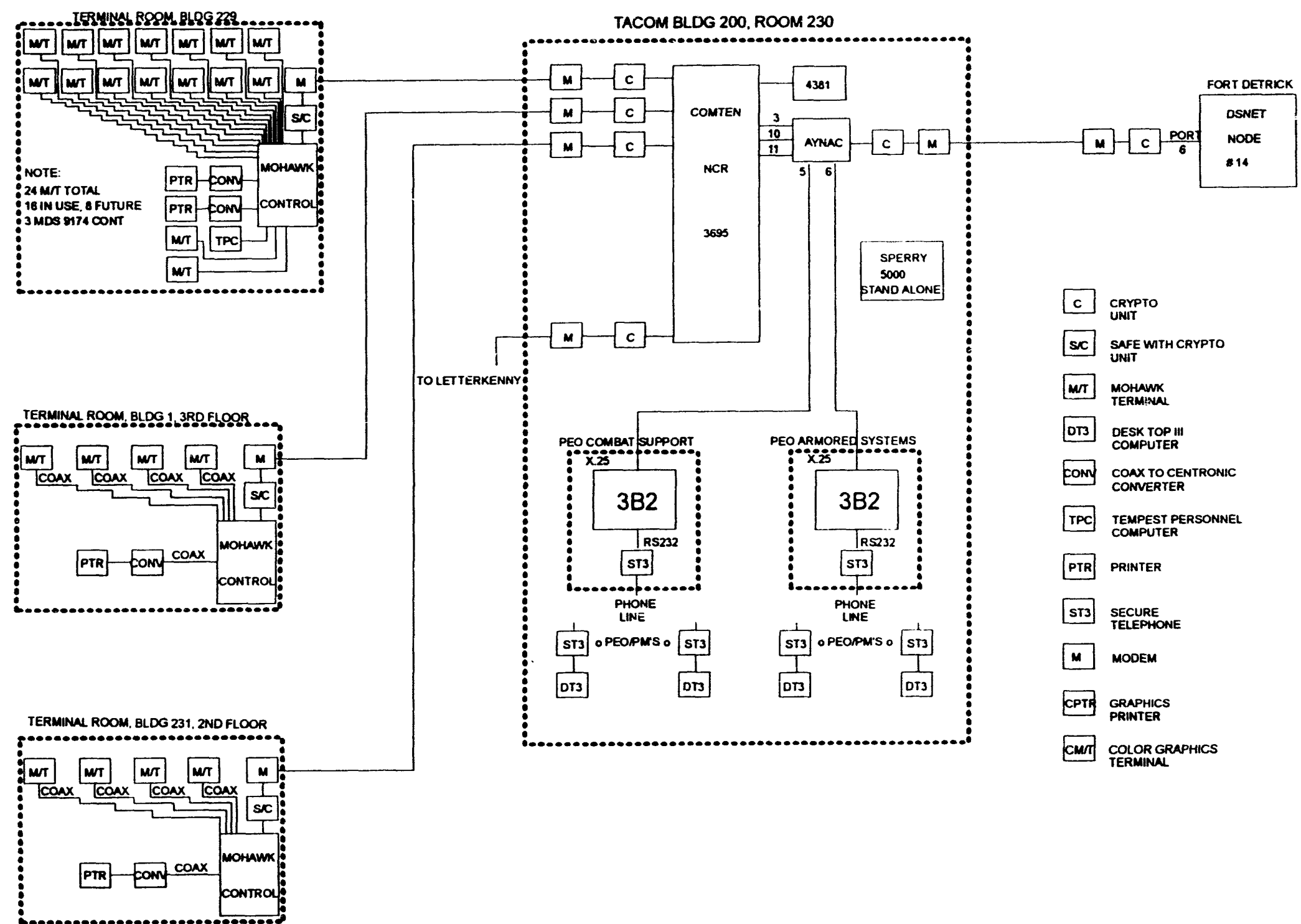

Figure 10. Warren AMPMOD Connectivity. 


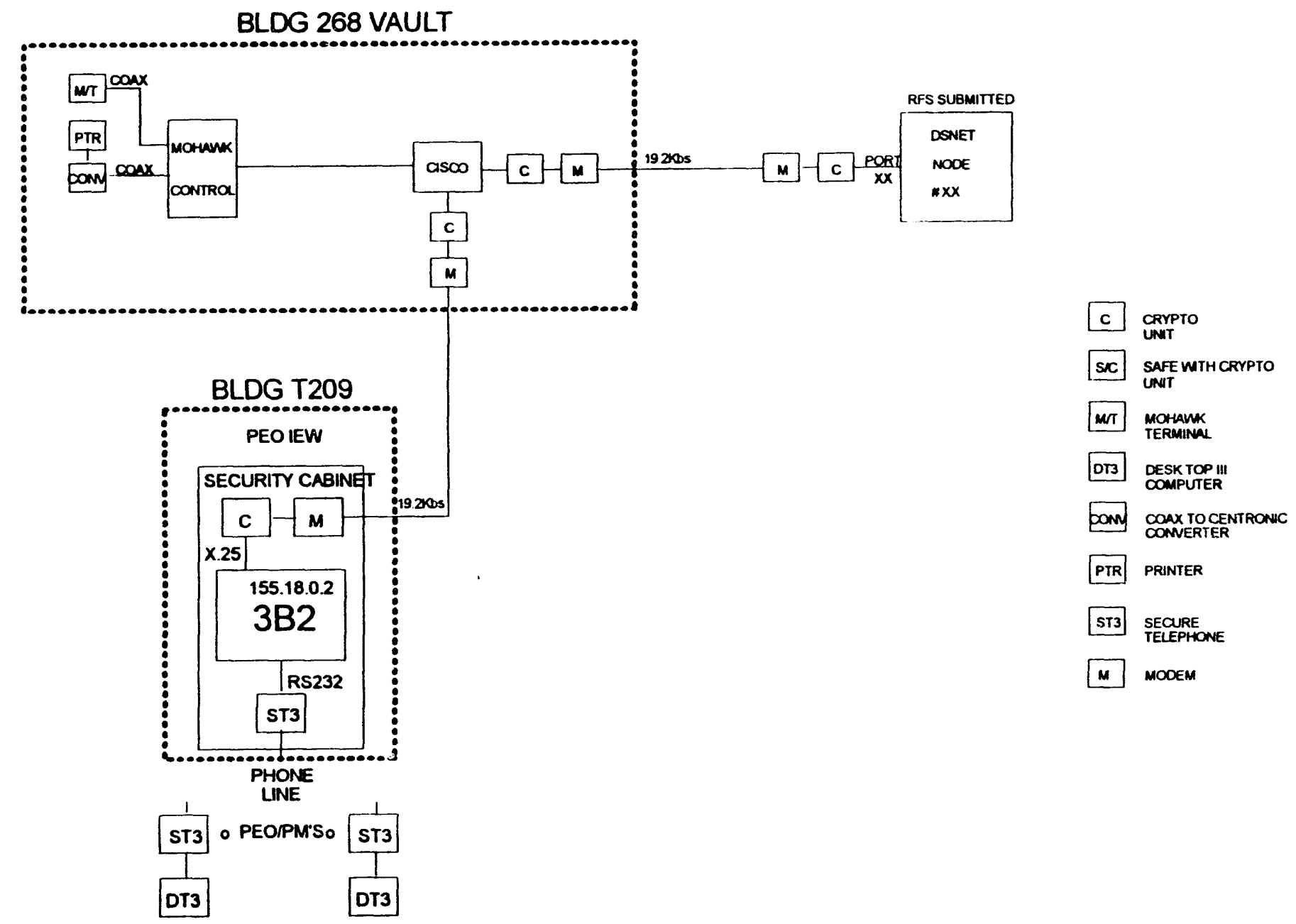

Figure 11. Vint Hill AMPMOD Connectivity. 


\subsection{EQUIPMENT}

The sites consisted of a mix of the following major end items of equipment and software:

Aydin Network Access Component (AYNAC)

NCR COMTEN Front end processors

IBM 4381 Host Computers

Mohawk Data Terminals and Printers

Tempest Personnel Computers (TPC)

CRYPTOS and Modems

The following software was installed on the IBM host computers:

VTAM

TSO

ISPF

AYNAC Control Program

The following software was installed on the Comtens:

ACF/NCP PEP GEN to support the AYNAC port.

The following software was installed on the AYNAC units:

Binary Synchronous Communications protocol support software HFP protocol support software

TCP/IP protocol software 


\section{RECOMMENDATIONS}

\subsection{CISCO REPLACEMENT OF AYNAC UNITS}

Cisco units should replace all fielded AYNAC units.

The AYNAC, as presently configured for AMPMOD, provides connectivity and access via DSNET1 for asynchronous terminals. It also provides the interface for the IBM family of synchronous terminals via cluster controllers and IBM hosts via front end communications processors. It enables a variety of standard terminal devices and computer systems to connect to and communicate through the DDN. It also serves as a data buffer and multiplexer. Up to 16 subscriber (user) devices can be connected to the AYNAC, each through a full duplex, serial input/output ( $\mathrm{I} / \mathrm{O})$ port. These connections provide the standard data interface such as RS-232, RS-449, and MIL-STD-188. One additional port is provided to communicate synchronously with the DDN node at standard data rates from 2400 to 56000 bits per second (bps). This interface uses the standard X.25 protocol and also provides the TCP/IP support software for the applications programs located on the hosts.

Described in terms of ordered data flow, the ACP exchanges data with the AYNAC using HFP. The AYNAC is connected to a port on either the COMTEN or IBM host in Binary Synchronous Communications (BSC) mode. The COMTEN is in turn channel attached to the IBM MVS host and communicates with the ACP using IBM VTAM. The data flows from the IBM host, through the AYNAC, CRYPTOS, and modems to its destination via the DSNET. The data will arrive from the packet-switched network (DSNET) into a modem, CRYPTO, AYNAC, and then sent to the remote host.

The AYNAC units located at host sites (I.E. Fort Monmouth, Redstone, Warren, St Louis, and Rock Island) use three (3) ports on the subscriber side. Ports 3 and 11 connect to the host. Port 10 connects to a cluster controller. All these units attach to a front end communications processor. Units located at non-host sites provide DDN access for the IBM type terminals via a cluster controller. These sites use from one (1) to five (5) ports on the AYNAC unit.

The AYNAC unit, during the beginning of this task, did not provide X.25 standard service on the subscriber side. PM-AIM initiated a contract to upgrade these units for this service. This enhancement would support PEO/PM connectivity requirements. The AYNAC upgrade was to provide all existing AYNAC functionality for eight (8) subscriber ports as well as six (6) serial communication ports providing DDN X.25 interface. All six (6) ports, being fully configurable, would enable five (5) hosts running DDN X.25 to be attached as subscriber hosts with the remaining $X .25$ port acting as the network interface.

Due to contractor non-performance (not meeting delivery dates), the AYNAC upgrade contract was canceled while ORNL performed this survey task. A decision made to use Army gateway program equipment during the execution of this task. The AYNAC units will be replaced with Cisco routers. 


\subsection{SUGGESTED FLOORPLANS}

Recommended AT\&T 3B2 location floor plans were also developed (Figures 12-23) to take advantage of existing computing facility layouts. 


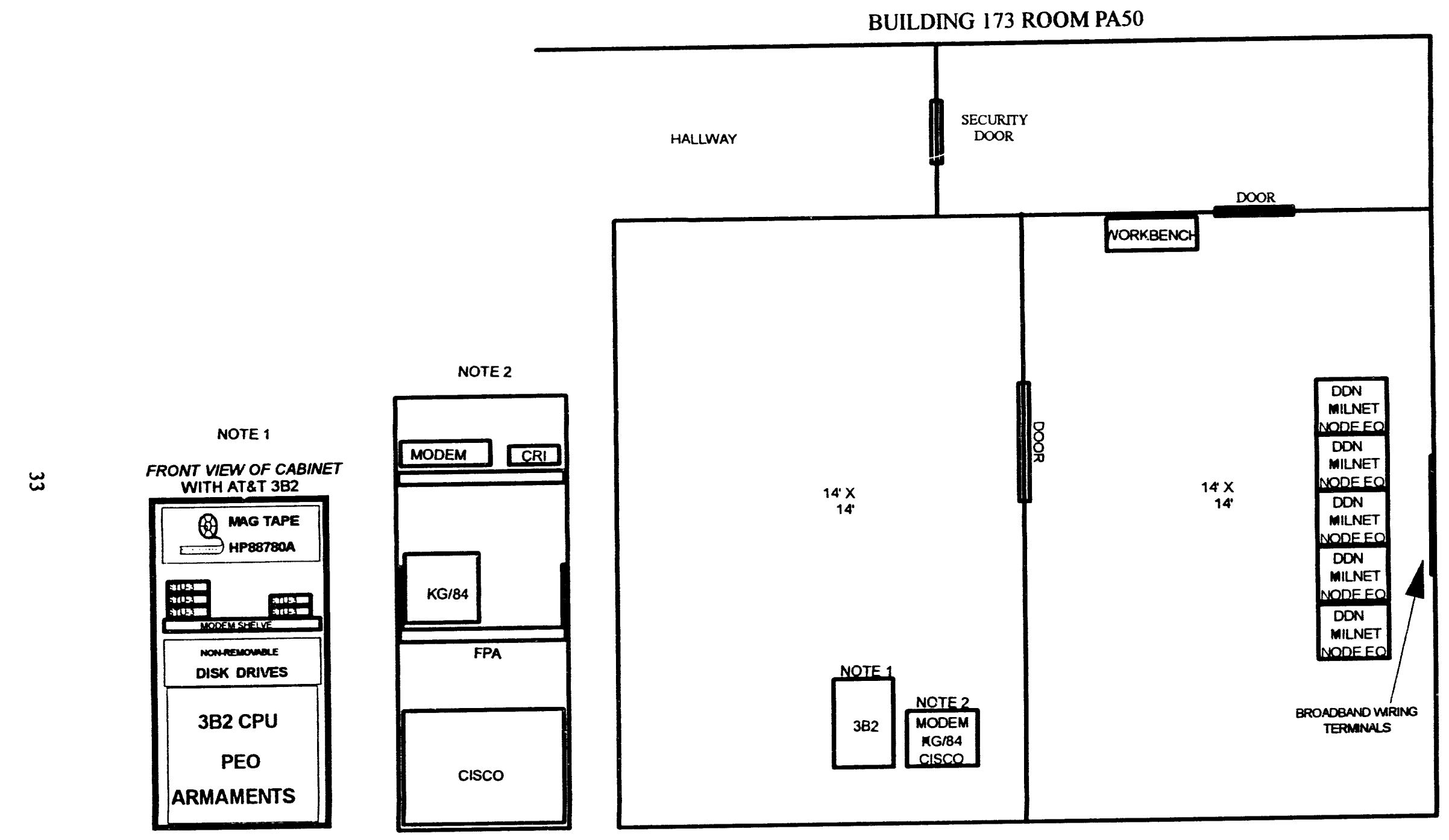

Figure 12. Picatinney Arsenal - PEO Armaments. 
VAIL HALL BUILDING

DOOR

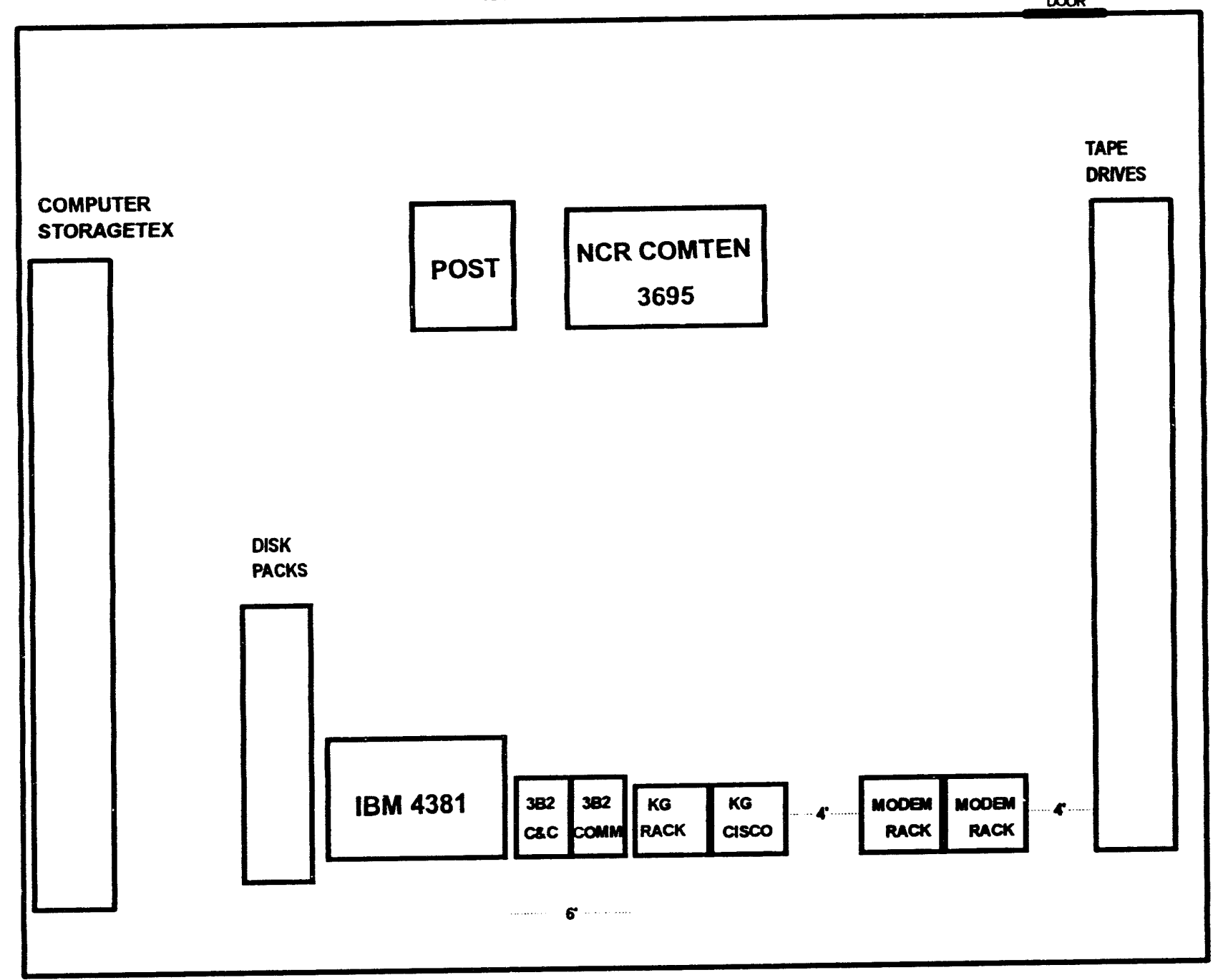

Figure 13. Fort Monmouth - PEO Communications

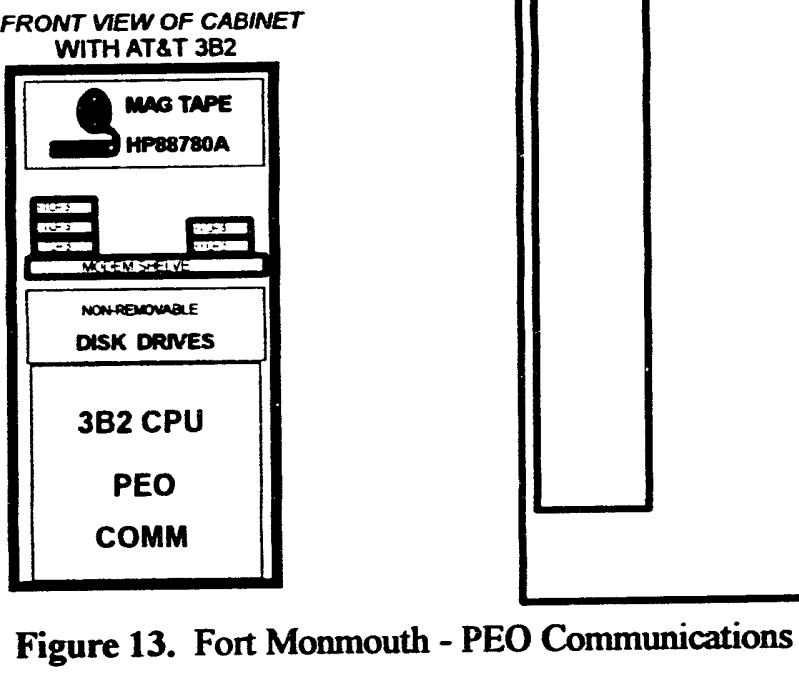




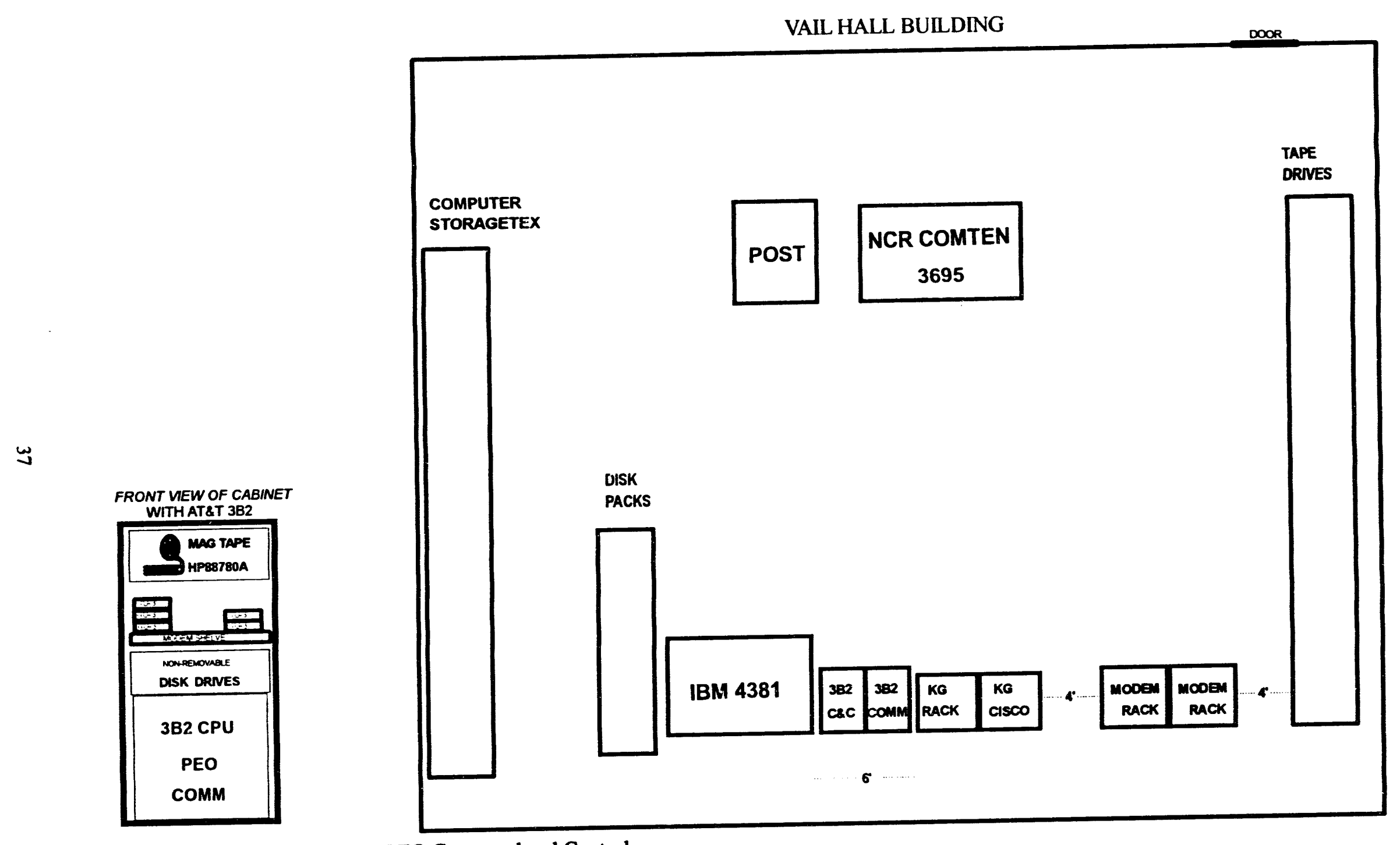

Figure 14. Fort Monmouth - PEO Command and Control 
BUILDING 4488 ROOM A343

FRONT VIEW OF SAFE

WITH AT\&T $3 B 2$

\begin{tabular}{|c|c|}
\hline SWTEN & WW: \\
\hline \multicolumn{2}{|c|}{$3 B 2 \mathrm{CPU}$} \\
\hline & \\
\hline \multicolumn{2}{|c|}{ FIRE SUPPORT } \\
\hline (8) & \\
\hline & NOLF \\
\hline DISK & RIVES \\
\hline KG-84 & STulimusac \\
\hline
\end{tabular}

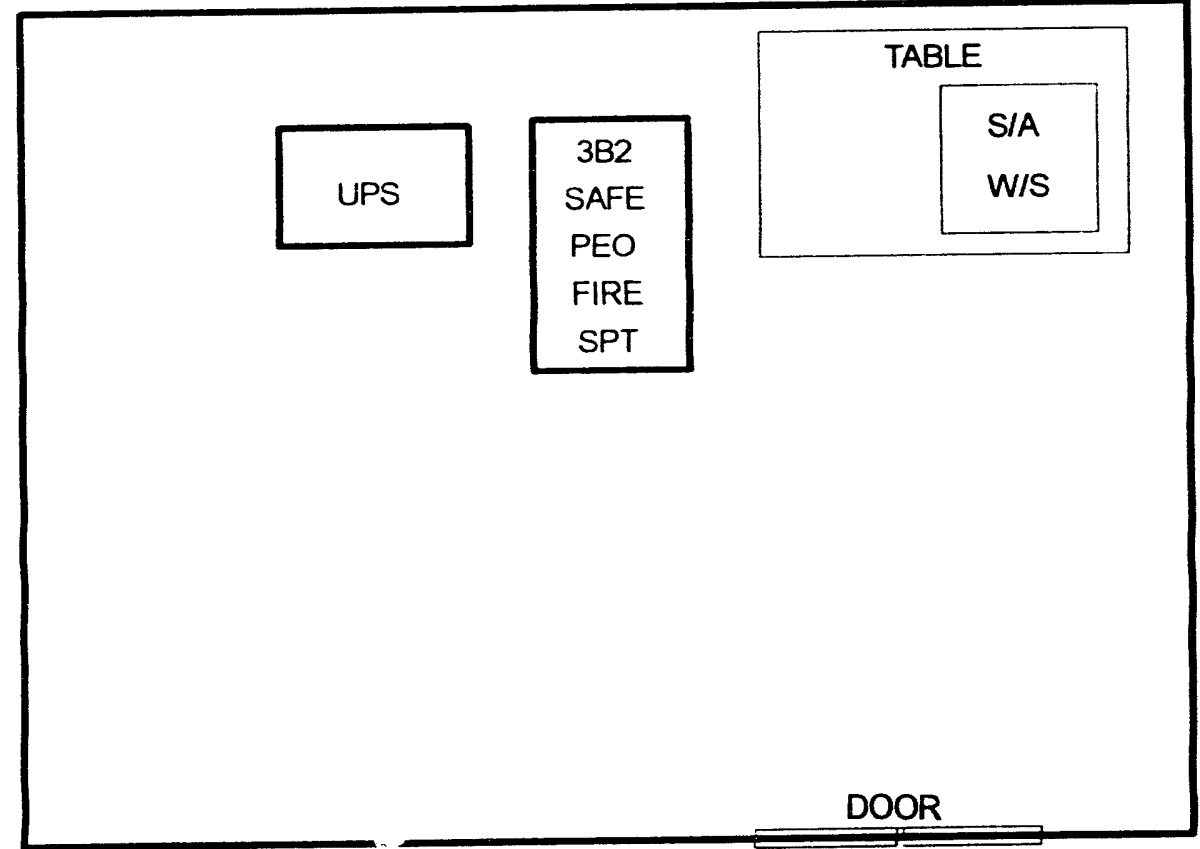

Figure 15. Redstone Arsenal - PEO Fire Support Systems 


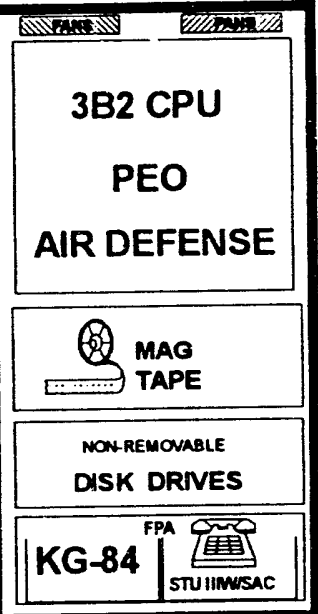

BUILDING 5250 ROOM B339

DOOR

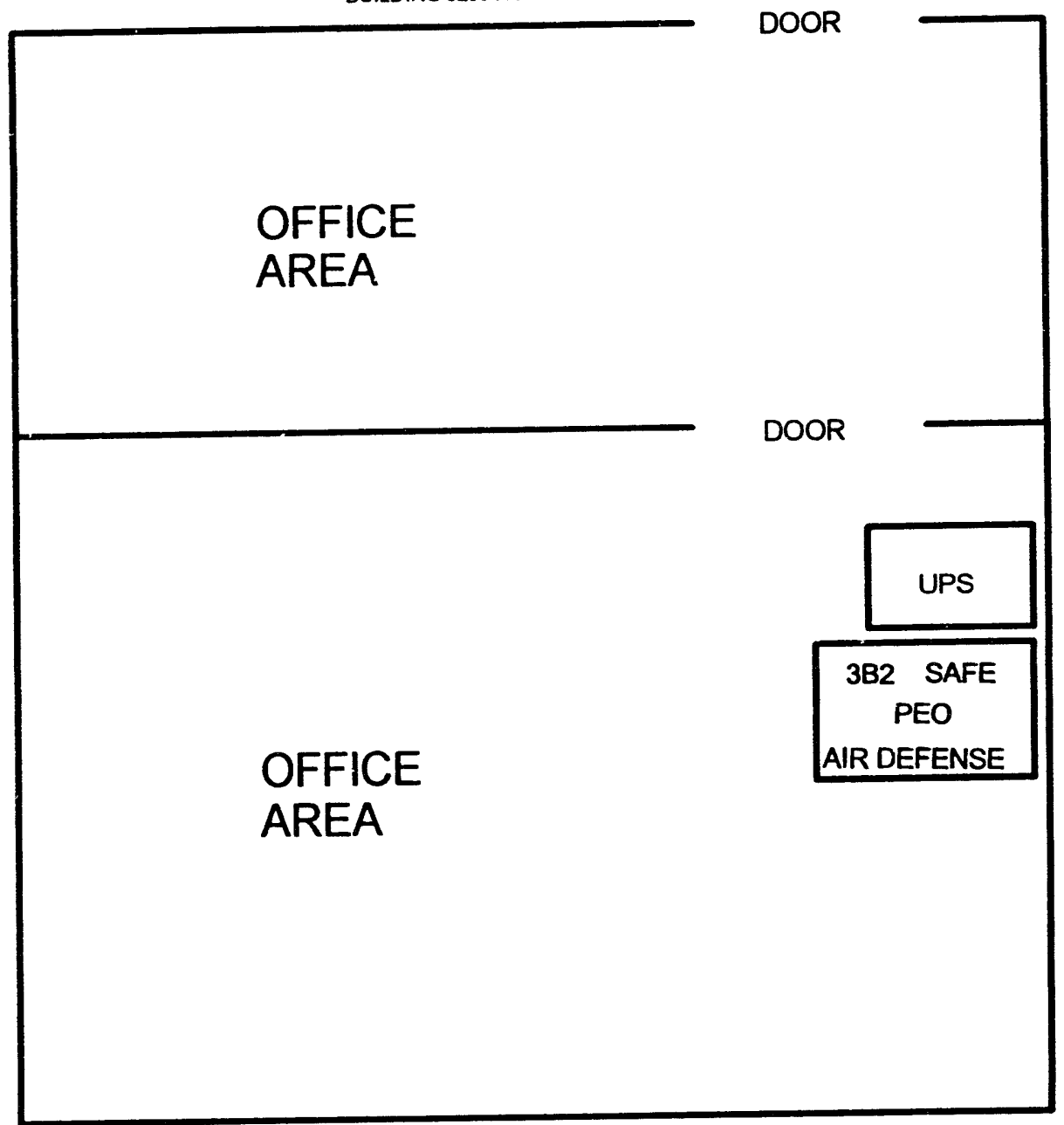

Figure 16. Redstone Arsenal - PEO Air Defense Systems 


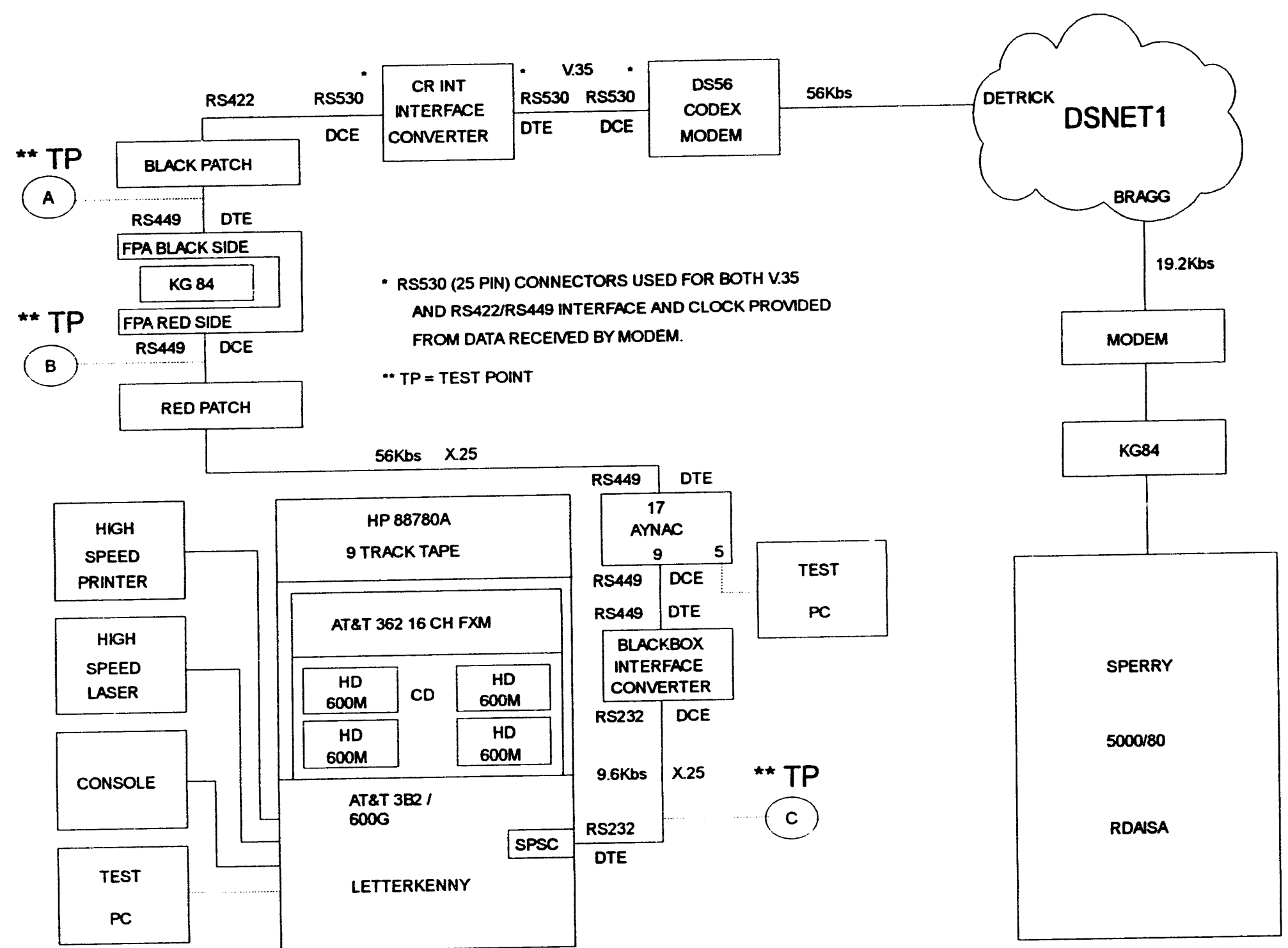

Figure 17. Letterkenny Army Depot - Systems Information Management Agency 


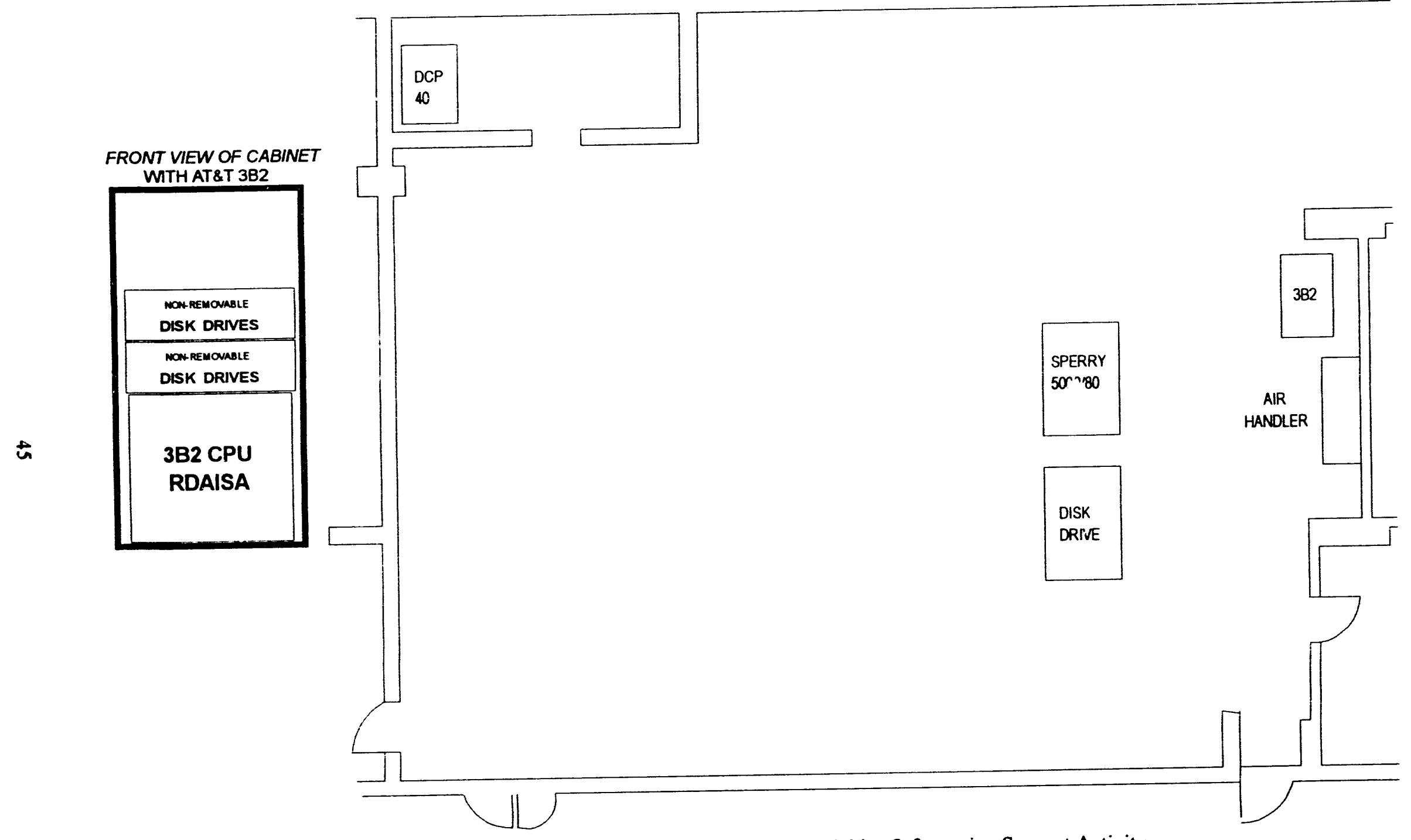

Figure 18. Radford Army Ammunitions Plant - Research, Development and Acquisition Information Support Activity. 


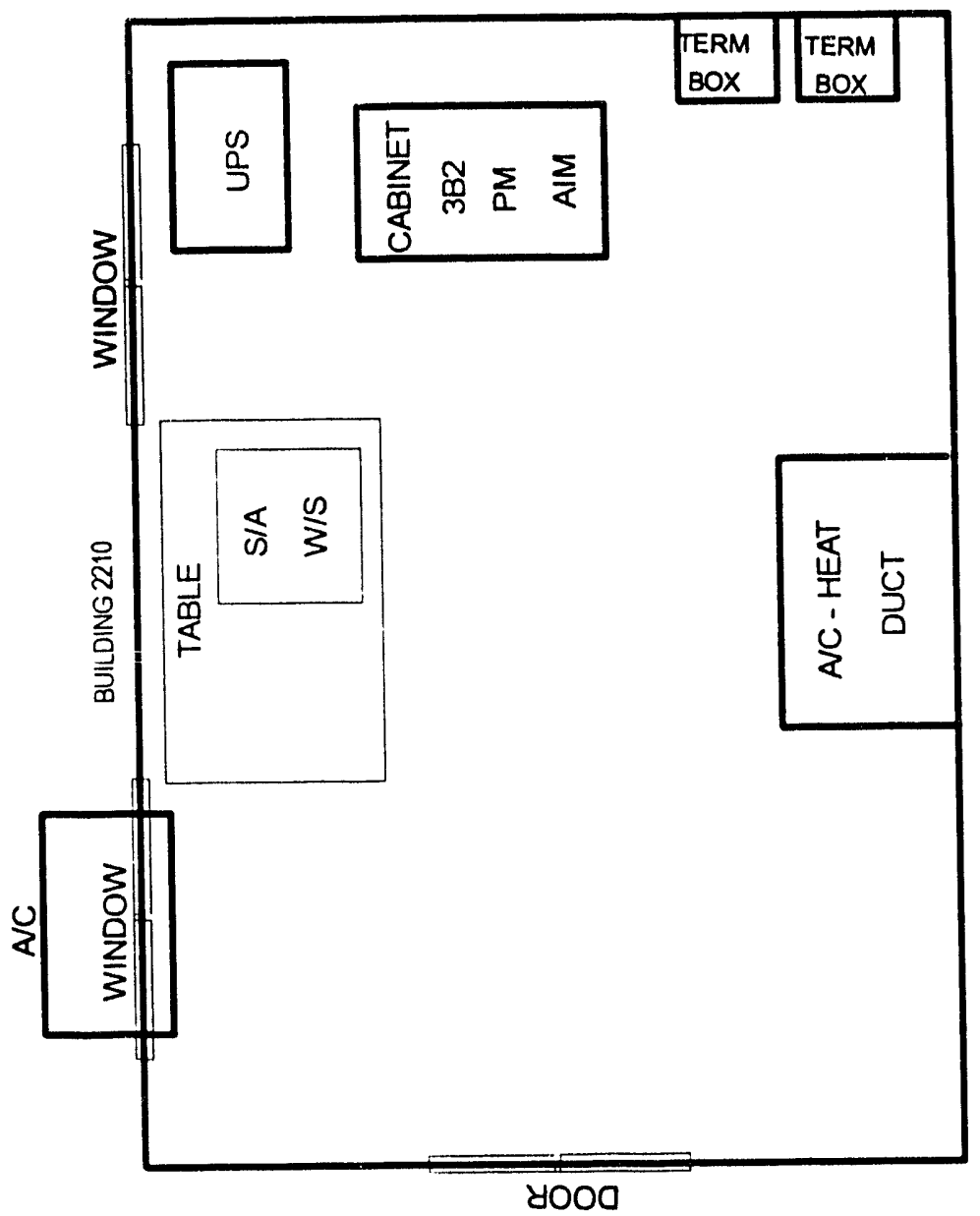

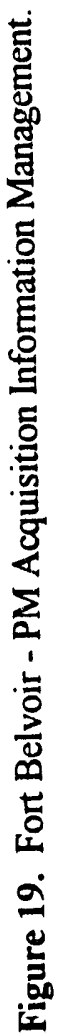


BUILDING 105 ROOM B-29

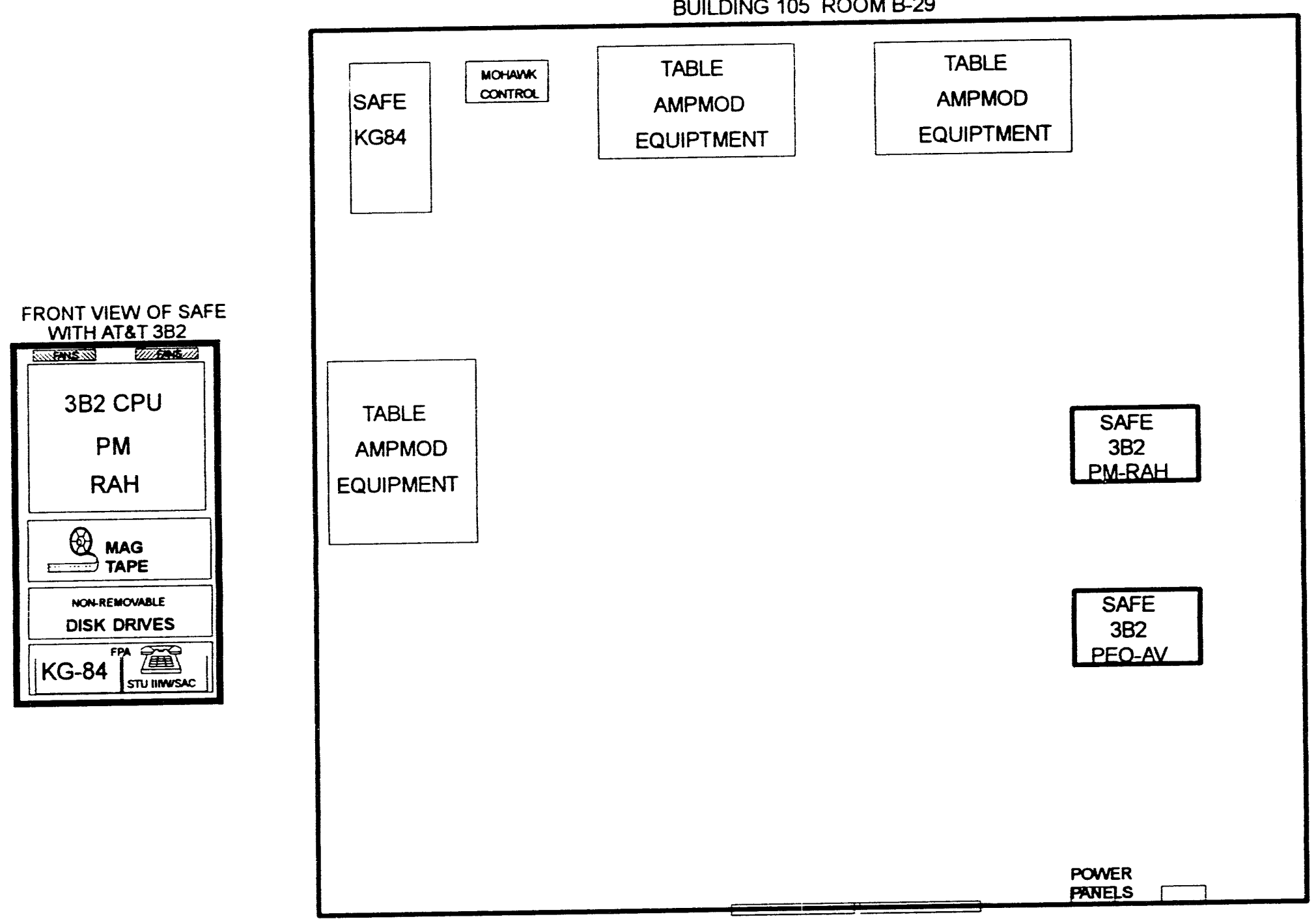

DOUBLE DOOR

Figure 20. St. Louis Federal Center - PEO Aviation Support Command 


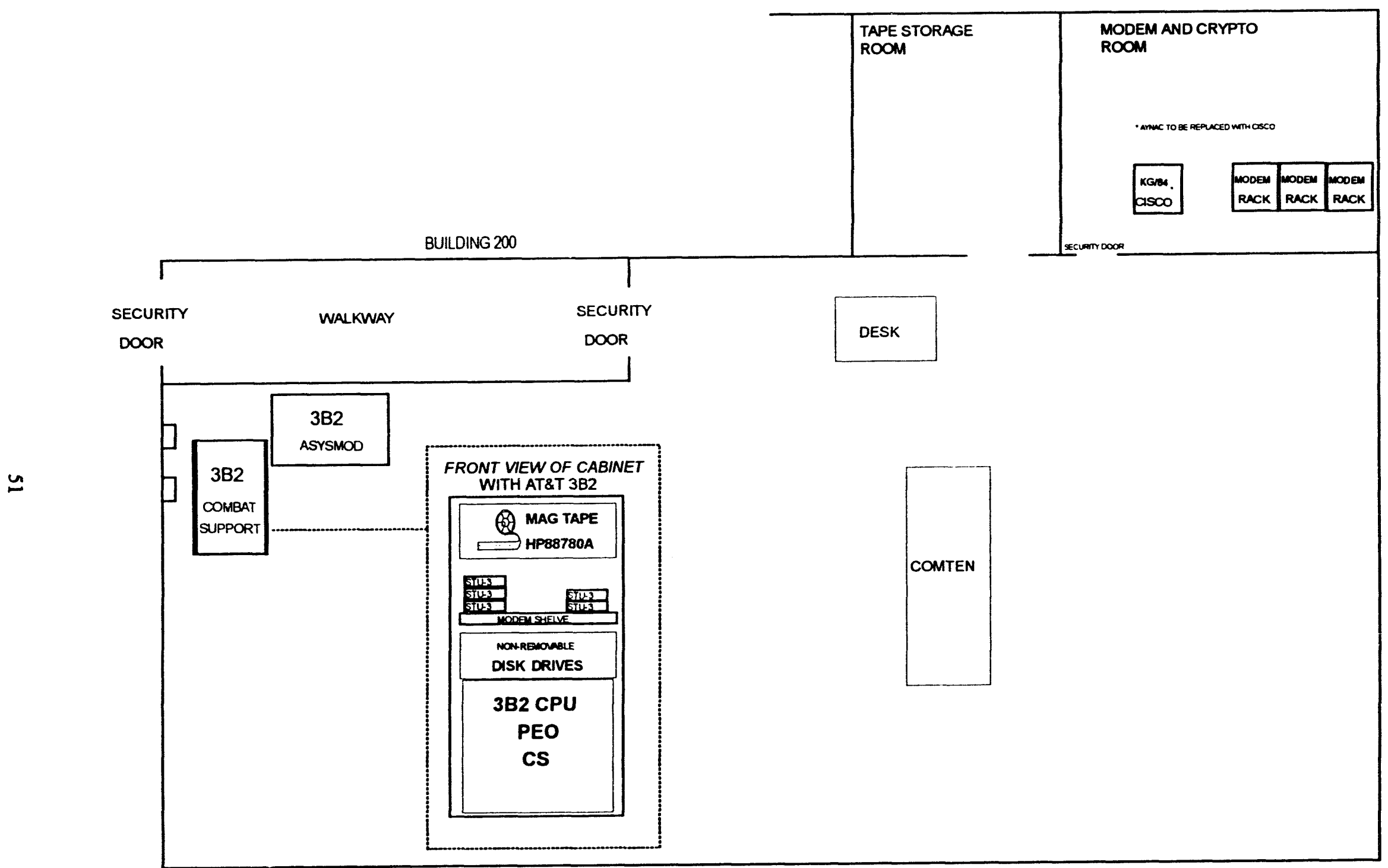

Figure 21. Tank and Automotive Command - PEO Combat Support 


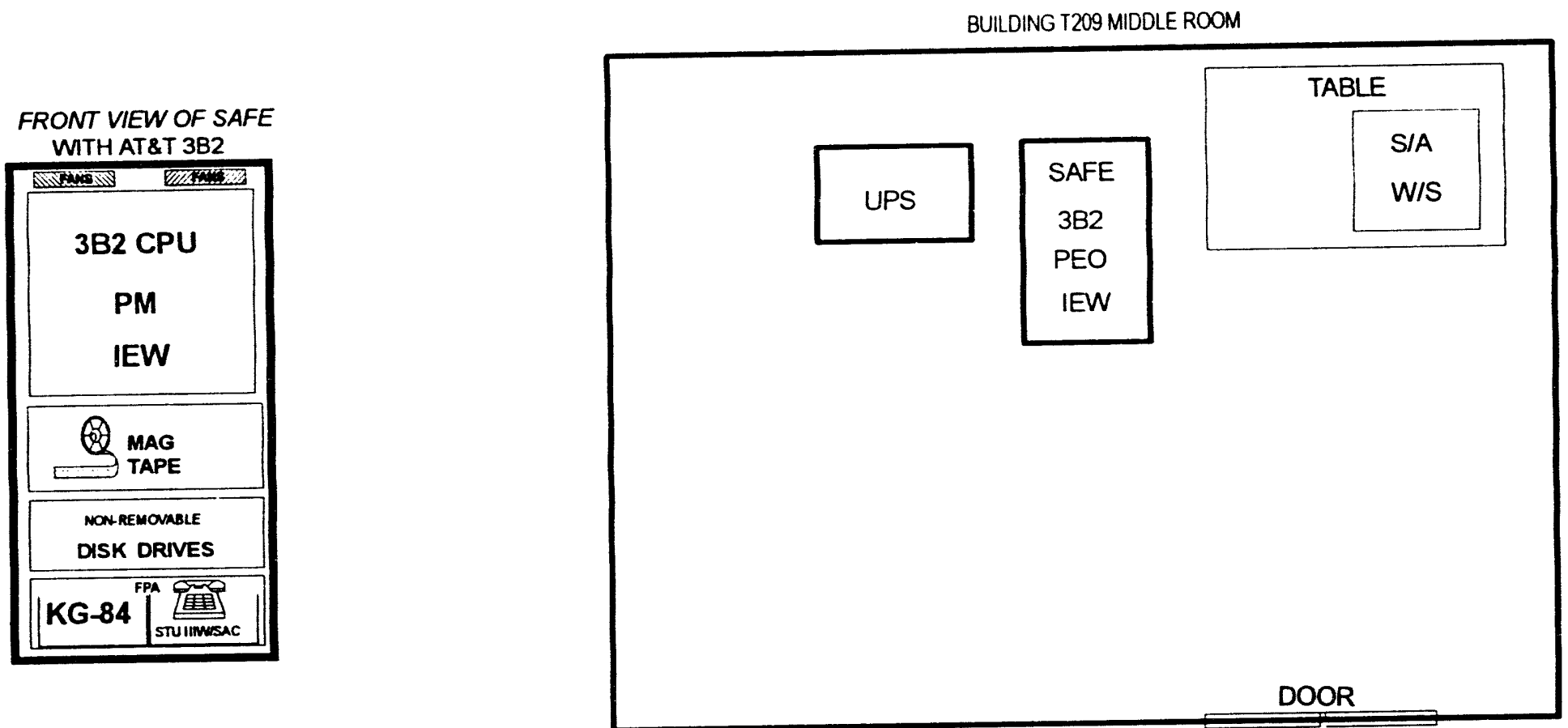

Figure 23. Vint Hill Farms - PEO Intelligence and Electronic Warfare. 


\subsection{OVERALL AIM SITE DSNET1 CONNECTIVITY REQUIREMENTS}

Recommended AIM site DSNET connectivity is summarized in diagrammatic form (Figure 24). 


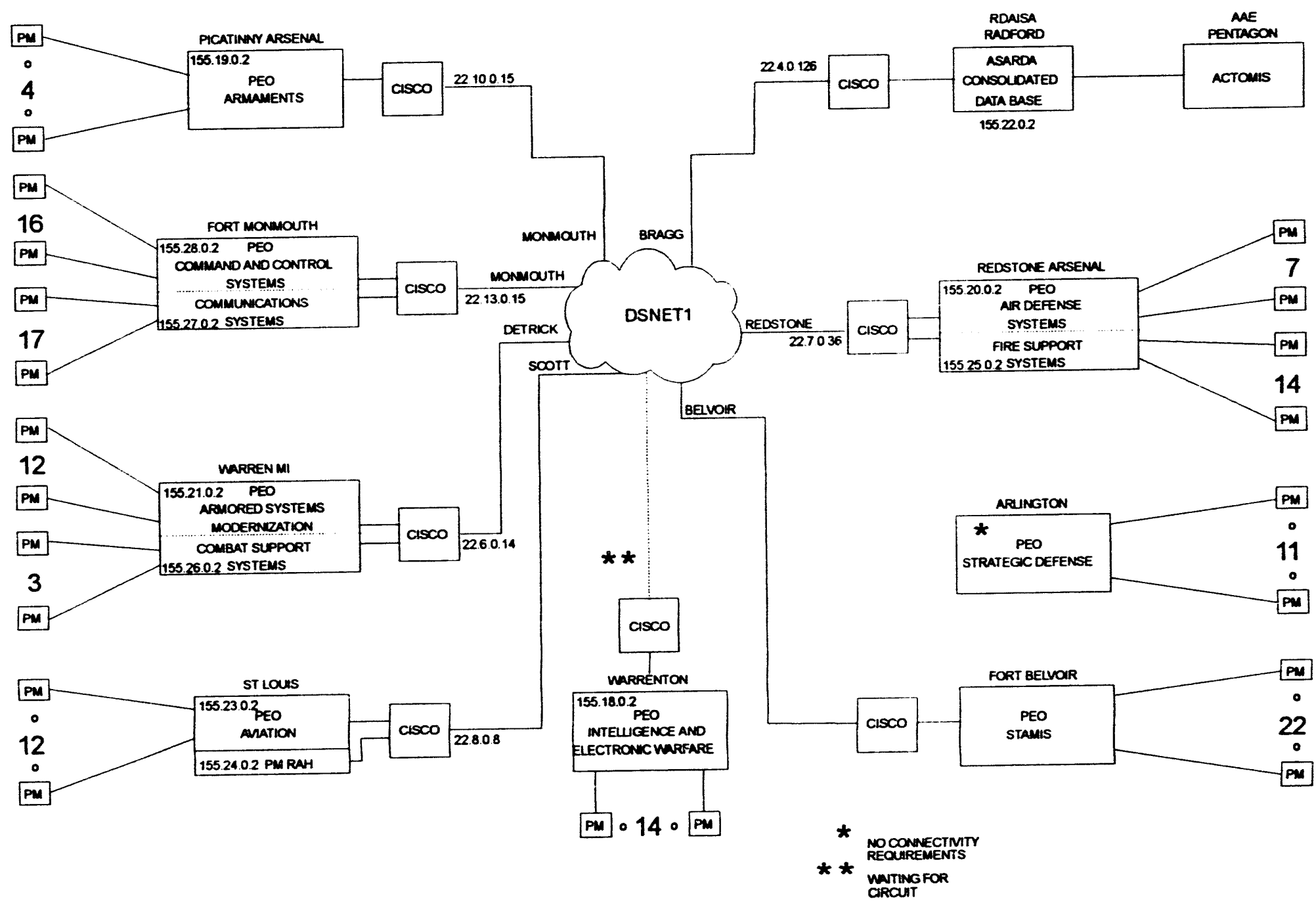

Figure 24. Recommended AIM Site DSNETI Connectivity 


\subsection{ADDITIONAL TELECOMMUNICATIONS RESOURCE REQUIREMENTS}

Additional tclecommunications resources -- hardware and software -- are necessary to support these requirements.

\subsubsection{Additional Hardware}

Additional hardware equipment requirments:

ITEM

Upgraded Comten Front Ends

AT\&T 3B2 Hosts Computer

Crypto Units, KG-84A

Fixed Plant Adaptor (FPA)

Secure Telephone Unit STUIII

RS232-449 Interface Converters

Modems

Security Containers

\section{OUANTITY}

5

12

10

8

10

11

10

5

Additional equipment broken out by location:

\begin{tabular}{lcccccccc} 
INSTALLATION & CISCO & 3B2 & KG84 & FPA & STU & IC & SC & MODEM \\
\hline Fort Belvoir & & 1 & & & & & & \\
Fort Monmouth & 1 & 2 & & & 2 & 2 & & \\
Picatinny Arsenal & 1 & 1 & & & 1 & 1 & & \\
Radford & 1 & 1 & & & & 1 & & \\
Redstone Arsenal & 1 & 2 & 4 & 3 & 2 & 2 & 2 & 4 \\
St. Louis Federal Center & 1 & 2 & 4 & 3 & 2 & 2 & 2 & 4 \\
$\quad \begin{array}{l}\text { Tank and Automotive } \\
\quad 1\end{array}$ & 2 & & & 2 & 2 & & \\
$\quad$ Command & 1 & 1 & 2 & 2 & 1 & 1 & 1 & 2 \\
$\quad$ Tint Hill Farms & 1 & 1 &
\end{tabular}

NOTE: FPA - Fixed Plant Adapter

IC - Interface Converter

SC - Security Container

\subsubsection{Additional Software}

For the AT\&T 3B2 Computer:

WIN/3B STREAMS TCP/IP

Disk and File Management (DFM)

Network Service Utilities (NSU)

User Environment Utilities (USRENV)

Kermit

For the DTIII: 
Communication Program that supports Kermit

\subsubsection{Security Containers}

The connectivity of the $3 \mathrm{~B} 2$ computers to DSNET1, and the processing of classified acquisition data, dictates that the 3B2s', and any attached devices. must be maintained at the secret level. Five of the surveyed areas do not have 24 hour, manned, open storage capability or vauits. The following site require security containers:

\section{LOCATION}

Huntsvillc. AL

Huntsville, AL

St. Louis, MO

St. Louis, MO
INSTALLATION

Redstone Arsenal

Redstone Arsenal

St. Louis Federal Center

St. Louis Federal Center

\section{ACTIVITY - PEO}

Fire Support Systems

Air Defense Systems

Aviation Support Command

Aviation Support Command -

Reconnaissance Aircraft Helicopter

An alternative to securing the entire telecommunications area is to locate the security sensitive equipment inside of a security container of safe (figure 25). the KG84 provides the secure interface to DSNETI and the STU III (data only with Secure Access Control System (SACS)) to the workstations certified to operate at the secret level.

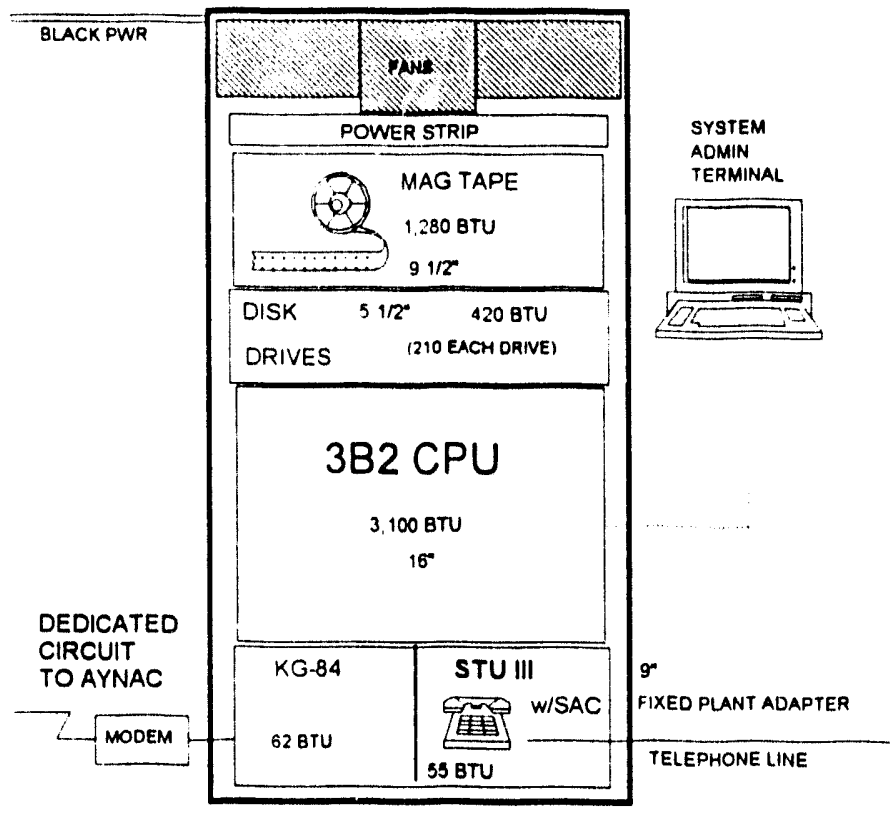

Figure 25. Proposed Security Containcr for AT\&T 3B2 


\section{CONCLUSIONS}

Each of the nine sites visited will require additional and software for DENETI connectivity. Letterkenny Army Depot was the only site not requiring additional hardware. The installations most likely to go on-line for testing after July 1992 are Tank and Automotive Command, Letterkenny Army Depot, and Radford Army Ammunitions Plant. 


\section{INTERNAL DISTRIBUTION}

1.

3. G. A. Dailey

4. J. L. Duncan

5. R. T. Goeltz

6. R. K. Gryder

7-9. K. A. Hake (3)

10. B. G. Key

11. M. A. Kuliasha

12. D. E. Reichle
13. R. B. Shelton

14. B. E. Tonn

15. G. W. Westley

16. W. B. Wood

17. S. L. Yount

18. Central Research Library

19. Document Reference Section

20-21. Laboratory Records

22. Laboratory Records - RC

23. ORNL Patent Office

\section{EXTERNAL DISTRIBUTION}

24-26. T. Branning, Department of the Army, Project Manager AIM, Attn: SARD-IMO (AIM), Stop C-113, Ft. Belvoir, VA 22060-5895.

27. D. Howard, Department of the Army, Project Manager AIM, Attn: SARD-IMO (AIM), Stop C-113, Ft. Belvoir, VA 22060-5895.

28. Dr. Helen M. Ingram, Director, Udall Center for Studies in Public Policy, The University of Arizona, 803/811 East First Street, Tucson, AZ 85719.

29. Mr. Calvin D. MacCracken, President, Calmac Manufacturing Corporation, 101 West Sheffield Avenue, Englewood, New Jersey 07631.

30. Ms. Jacqueline B. Shrago, Director, Office of Technology Transfer, 405 Kirkland Hall, Vanderbilt University, Nashville, Tennessee 37240.

31. Dr. Martin Williams, Professor, Department of Economics, Northern Illinois University, DeKalb, Illinois 60115.

32. Office of Assist Manager for Energy Research and Development, DOE/ORO, P.O. Box 2001, Oak Ridge, Tennessee 37831-8600.

33-34. Office of Scientific and Technical Information, U.S. Department of Energy, P.O. Box 62, Oak Ridge, Tennessee 37831. 

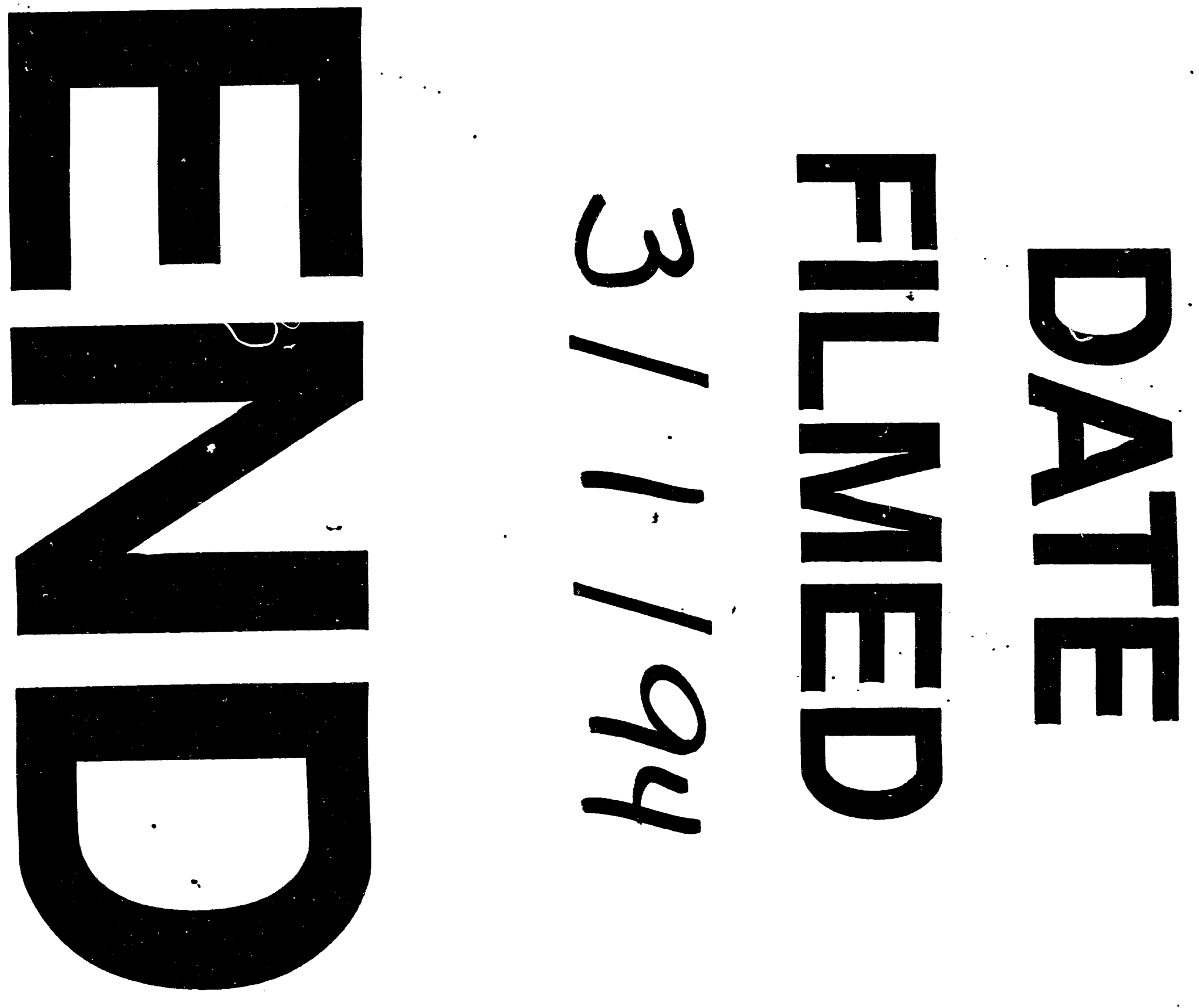
